\title{
A new centrosaurine ceratopsid from the Oldman Formation of Alberta and its implications for centrosaurine taxonomy and systematics
}

\author{
Michael J. Ryan and Anthony P. Russell
}

\begin{abstract}
Centrosaurus brinkmani (sp. nov) is distinguished from Centrosaurus apertus by key features of its cranial ornamentation, including the shape and orientation of the postorbital horn and parietal ornamentation at parietal locus 3 , the shape of the parietal ornamentation at locus 2, and the possession of accessory parietal ossifications developed as short spines on the caudal parietal ramus. This species is restricted to the Oldman Formation of southern Alberta and is the oldest ceratopsid represented by diagnostic material in Canada. Phylogenetic analysis of the Centrosaurinae suggests that the development of spike-like ornamentation at the parietal locus 3 parietal locus is inversely related to the development of the P1 parietal ornamentation.
\end{abstract}

\begin{abstract}
Résumé : Centrosaurus brinkmani (sp. nov) se distingue de Centrosaurus apertus par d'importants caractères de son ornementation crânienne dont la forme et l'orientation de la corne post-orbitale et de l'ornementation pariétale au locus pariétal no 3, la forme de l'ornementation pariétale au locus no 2 et la présence d'ossifications pariétales accessoires formant de courtes épines sur la rame caudale pariétale. La présence de cette espèce se limite à la Formation d'Oldman du sud de l'Alberta et il s'agit du plus ancien Cératopsidé représenté par du matériel diagnostique au Canada. L'analyse phylogénique des Centrosaurinés indique qu'il existe une relation inverse entre le développement de l'ornementation en forme de pointe au locus pariétal no 3 et le développement de l'ornementation au locus pariétal no 1.
\end{abstract}

[Traduit par la Rédaction]

\section{Introduction}

The late Campanian Judith River Group (Fig. 1) of Alberta has yielded over three dozen dinosaur taxa (Ryan and Russell 2001). Most have been recovered from the Dinosaur Park Formation (notably from Dinosaur Provincial Park), where isolated elements, partial and complete skeletons, and bone beds are commonly encountered. The underlying Oldman Formation has numerically fewer recognized taxa, partly because of the relative lack of exposure compared with the Dinosaur Park Formation. Bone beds and skeletons are found less frequently in the Oldman Formation and, when they are encountered, diagnostic material is not always present (Ryan and Russell 2001).

Among the ceratopsids recovered from the Judith River Group are the chasmosaurines Chasmosaurus belli, C. irvinensis, and $C$. russelli, which appear to be stratigraphically partitioned within the Dinosaur Park Formation (Holmes et al. 2001). The genus is not known from the Oldman Formation, and no chasmosaurine bone beds are known from the Judith River

Received 17 August 2004. Accepted 15 February 2005.

Published on the NRC Research Press Web site at http://cjes.nrc.ca on 4 November 2005.

Paper handled by Associate Editor H.-D. Sues.

M.J. Ryan, ${ }^{1,2}$ andA.P. Russell. University of Calgary, 2500

University Dr. NW, Calgary, AB T2N 1B4, Canada.

${ }^{1}$ Corresponding author (e-mail: mryan@cmnh.org).

${ }^{2}$ Present address: Cleveland Museum of Natural History, 1

Wade Oval Dr., University Circle, Cleveland, OH 44106, USA.
Group. The centrosaurines Centrosaurus apertus and Styracosaurus albertensis are commonly recovered from the Dinosaur Park Formation, where they also appear to be stratigraphically restricted to the lower and upper part of the formation, respectively (Ryan et al. 2001; Ryan and Evans 2005).

Diagnostic ceratopsid material is rare in the Oldman Formation and collected material has previously included only indeterminate centrosaurine specimens (Ryan and Russell 2001). One specimen of $C$. apertus (an almost complete skull, TMP 93.70.1) is known from the extreme southern part of the province, but it occurs in sediments that are equivalent in time to the lower part of the Dinosaur Park Formation in Dinosaur Provincial Park (Eberth and Hamblin 1993). Chasmosaurine specimens previously reported from the Oldman Formation (e.g., Anchiceratops, Langston, Jr. 1959) actually occur in sediments now recognized as belonging to the Dinosaur Park Formation (and are equivalent to the uppermost sediments of this formation in Dinosaur Provincial Park).

Excavations of two new paucispecific centrosaurine bone beds in the Oldman Formation of Alberta by the Field Experience Program of the Royal Tyrrell Museum of Palaeontology have yielded hundreds of disarticulated and mostly fragmentary specimens that represent a new species of Centrosaurus distinguished by characters of its supraorbital and parietal ornamentation.

In one quarry in bone bed (BB) 138 (Fig. 2) in Dinosaur Provincial Park, 27 juxtaposing 1-m grids were completely excavated between 1996 and 2000 and yielded 1042 elements. The material was recovered from a fine-grained sandstone and, although much of the material is fragmentary because 
Fig. 1. Temporal distribution of late Campanian centrosaurines in the Dinosaur Provincial Park region of southern Alberta. Grey bars indicate regional coal zones. Radiometric dates (in Ma) are taken from (a) Lerbekmo and Braman (2002), (b, c) Eberth and Braman (1993), and (d) Goodwin and Deino (1989). Stippling indicates marine shales. The figure incorporates palaeomagnetostratigraphic data from Braman et al. (1995) and Lerbekmo and Braman (2002). FM, Formation; GP, Group.

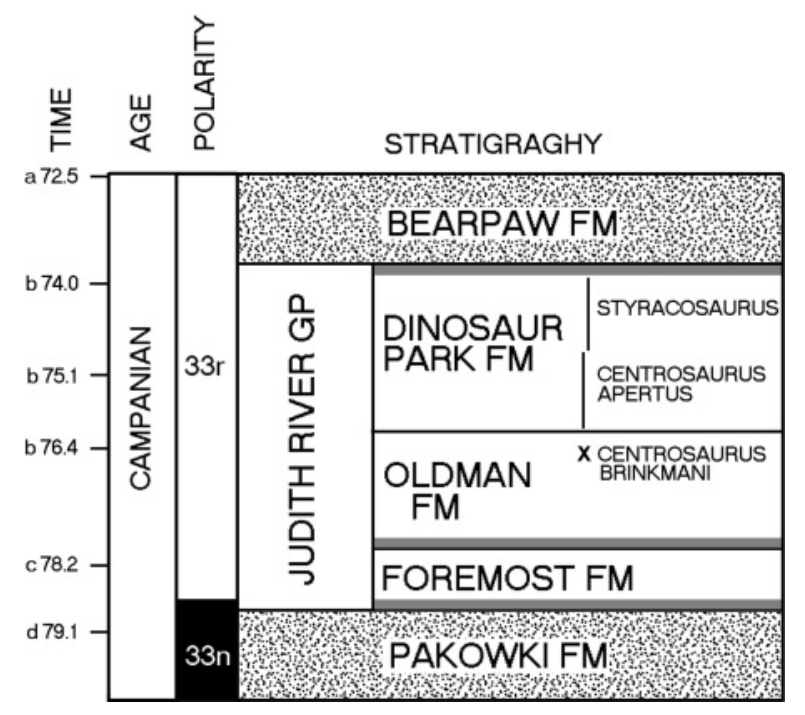

of pre-depositional processes, it is well preserved and undistorted. Of the 750 elements that could be identified to taxa, $689(92 \%)$ are ceratopsid and are referred to the new taxon.

The Milk River Ridge reservoir bone bed (MRR BB) in southern Alberta (Fig. 2) is unusual in that the bone-yielding substratum extends for approximately $50 \mathrm{~m}$ along the shoreline of a man-made reservoir. Exposure of the bone bed is partially dependant upon the water level in the reservoir. As a consequence of the MRR BB being located within the fluctuating water table of the reservoir, many of the elements recovered are broken owing to modern frost heave and the resulting cracks are infilled with precipitated calcite. In 1998, 370 elements were collected from 12 completely excavated, 1-m grids from two quarries excavated along the reservoir margin. Of the 222 elements that could be identified to taxa (at least to the level of family), 206 (93\%) are ceratopsid and are referred to the new taxon.

\section{Institutional abbreviations}

ANSP, The Academy of Natural Sciences, Philadelphia, Pennsylvania, USA.; CMN, Canadian Museum of Nature, Ottawa, Ontario, Canada; UCMP, Museum of Paleontology, University of California, Berkeley, California, USA.; MOR, Museum of the Rockies, Montana State University, Bozeman, Montana, USA.; NAMAL, North American Museum of Ancient Life, Thanksgiving Point, Utah; RSM, Royal Saskatchewan Museum, Regina, Saskatchewan, Canada; TMP, Royal Tyrrell Museum of Palaeontology, Drumheller, Alberta, Canada.
Fig. 2. Locality map for bone bed 138 and the Milk River Ridge reservoir bone bed, southern Alberta. BB, bone bed.

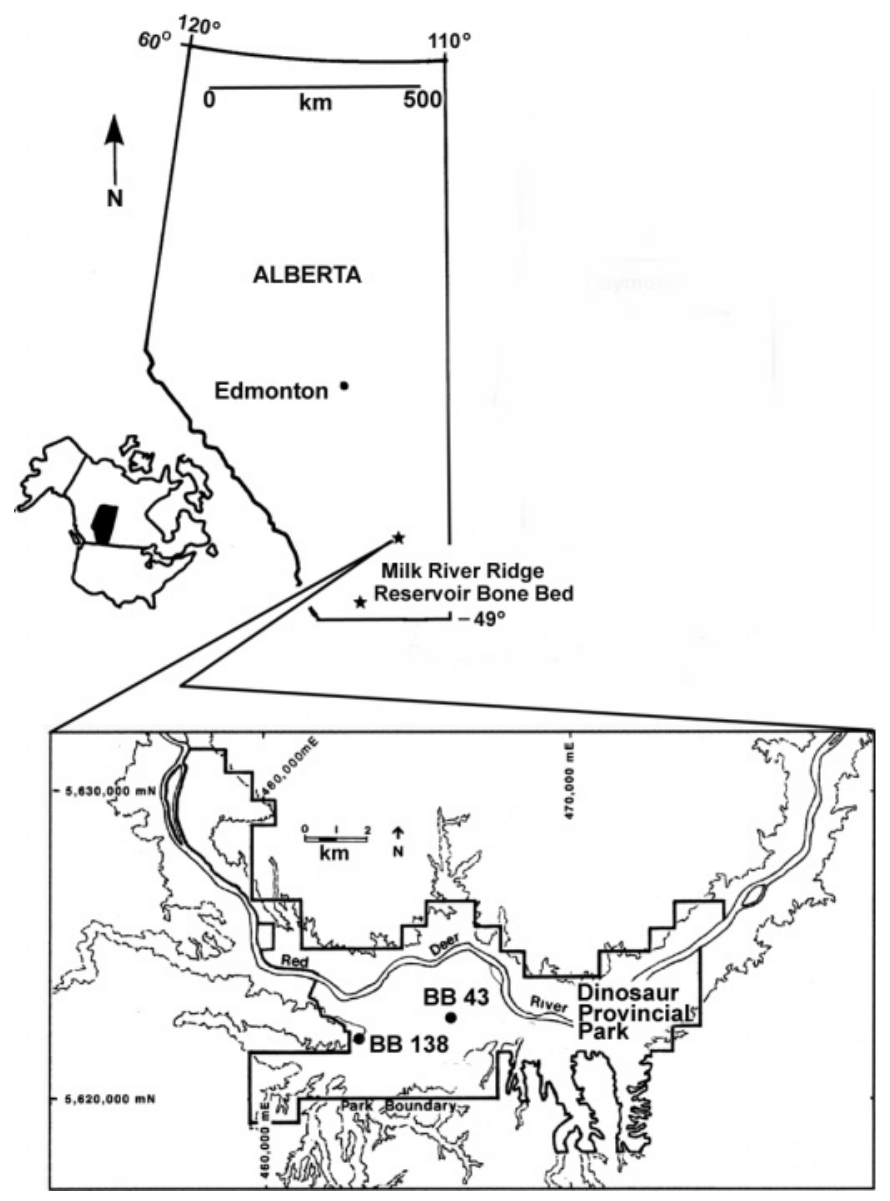

\section{Systematic paleontology}

Ornithischia Seeley, 1888

Ceratopsia Marsh, 1890

Neoceratopsia Sereno, 1986

Ceratopsidae Marsh, 1888

Centrosuarinae Lambe, 1915

Genus Centrosaurssus Lambe, 1904

DIAGNOSIS: After Dodson (1990, p. 234): "those species found in Alberta that have the thickened caudal parietal margin with hook-like processes projecting caudally and hornlike processes projecting rostrally."

AMENDED DIAGNOSIS: Centrosaurine ceratopsid with parietal process 1 (P1) (see Sampson et al. 1997 and Ryan et al. 2001 for numbering of parietal processes) developed as a large procurving hook (one of the pair may rarely be absent from either side, e.g., CMN 971). Unlike all valid centrosaurines, except Styracosaurus, the nasal horn core is erect, elongate, and laterally compressed with the apex dorsally oriented or inflected rostrally. Unmodified adult supraorbital horn cores have an inflated pyramidal shape with rounded apices.

TYPE SPECIES: Centrosaurus apertus Lambe, 1904 
AMENDED SPECIFIC DIAGNOSIS FOR CENTROSAURUS APERTUS: Parietal P2 processes developed and medially curled as hooks, in the plane of the frill, from the posterior parietal ramus on either side of the midline parietal bar. Similarly, developed hooks on $S$. albertensis are never as robust. Parietal process 3 unmodified from a small, depressed, crescent-shaped epoccipital. Unlike all centrosaurines, except Styracosaurus, the subadult supraorbital ornamentation is pyramidal, with a flat lateral and a convex medial surface.

TYPE SPECIMEN: NMC 971: a complete parietal.

DISTRIBUTION: Lower $30 \mathrm{~m}$ of the Dinosaur Provincial Park Formation, Alberta and Saskatchewan, Canada, and the timeequivalent middle "muddy unit" of the Oldman Formation, Manyberries region, Alberta, Canada. Known from multiple skulls, skeletons, and material from bone beds.

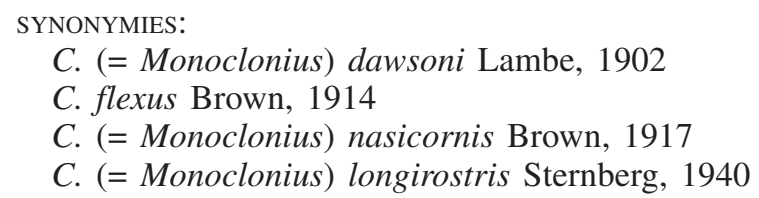

Centrosaurus brinkmani, sp. nov.

SPECIFIC ETYMOLOGY: For Donald Brinkman, in honour of his research illuminating the palaeoecology of the Late Cretaceous environments of Alberta.

DIAGNOSIS: Centrosaurine ceratopsid with supraorbital horn cores that, in adults, are inflated (but not elongated as in Zuniceratops or Triceratops) and project laterally over the orbit; subadult postorbital horn cores have an attenuated pyramidal shape with a slight lateral inflection of the distal one half; posterior parietal bar has a number of small accessory dermal ossifications that fuse along the caudal and dorsal surfaces and contribute to the substance of P1 and P2; these accessory ossifications can be variably developed as short spines that may or may not be fused along their adjacent margins; P3 is variably developed as a short tongue-like hook or tapered spike that is dorsolaterally oriented.

HOLOTYPE: TMP 2002.68.1 (Fig. 3b, 3c) is a large adult-sized parietal with a nearly complete midline bar and a partial posterior bar with left (L) P1-P3 processes and the partially eroded right $(\mathrm{R}) \mathrm{P} 1$ and $\mathrm{P} 2$. It lacks the extreme anterior margin of the midline bar that forms the posterior wall of the frontal fontanelle and the paper-thin lateral margins that define the medial margins of the supraorbital foramina. The overall size and shape of the underlying bone, excluding the ornamentation, is similar to that of $C$. apertus (see Sampson et al. 1997 and Ryan et al. 2001 for a complete description of this element).

REFERRED SPECIMENS: Unless otherwise noted, all the ceratopsid material from BB 138 in Dinosaur Provincial Park, Alberta, and the MRR BB near Warner, Alberta, is referred to C. brinkmani. Material is listed in Ryan (2003), a copy of which is on file with the Royal Tyrrell Museum of Palaeontology. Significant representatives of the parietal, postorbital, and supraorbitals include TMP 2002.68 .3 (Fig. 3a), TMP 2002.68.10 (Fig. 3d, 3e), and 2002.68.5 (Fig. 3f), respectively.
TYPe LOCAlity: Bone bed 138 (Fig. 2), Dinosaur Provincial Park, approximately $50 \mathrm{~km}$ from Brooks, Alberta, Canada (12 463090E, 5621680N (WGS 84)), Oldman Formation, $14.6 \mathrm{~m}$ below the contact with the Dinosaur Park Formation (645 $\mathrm{m}$ above sea level). The MRR BB (Fig. 2) near Warner, Alberta, approximately $180 \mathrm{~km}$ southwest of BB 138, is also from the Oldman Formation. Exact locality information of this bone bed is on file with the TMP.

DISTRIBUTION: As for the type and referred localities.

\section{Description}

C. brinkmani (Fig. 3-8) appears to be indistinguishable from $C$. apertus in all aspects of its anatomy, except for differences in its cranial ornamentation (nasal, parietal, and postorbital horn cores). Only these aspects of the anatomy are discussed.

\section{Nasal}

The nasal (Fig. 4) of $C$. brinkmani $(N=16$ adult-sized and 21 juvenile or adult-sized specimens (most of the latter are fragmentary)) closely resembles that of $C$. apertus in its unfused juvenile or subadult and fused adult forms (Fig. 4C$4 \mathrm{G}, 5 \mathrm{~A}$ ) and, based on the morphology of these elements, appears to have undergone a similar ontogenetic history (as outlined by Sampson et al. 1997; Ryan et al. 2001). The face of C. brinkmani (Fig. 5A) is dominated by an erect, laterally compressed nasal horn core with a blunt tip (missing on TMP 98.12.69), formed from the fusion of the opposing nasals, that sits over the posterior portion of the external nares, as it does in all centrosaurines. All juvenile and most adult specimens (Fig. 4C-4G, 5A) have gently recurved anterior and posterior margins resulting in most horns having an apex that is oriented at least slightly caudally. Anterolaterally, the nasal has a short rostral projection that overlaps the dorsomedial projection of the paired premaxillaries. Dorsomedially the nasal underlaps the prefrontal, dorsolaterally the lacrimal, and laterally contacts the posterior flange of the premaxilla. Ventrally the nasals roof the top and posterior margins of the nares. From the caudolateral narial margin, the nasals contribute the dorsal portion of a short, blunt, anteriorly directed narial process supported by the premaxilla from below, which is characteristic of the subfamily.

As is the case for $C$. apertus, both juvenile- and adultsized nasal horn cores (Fig. 4A-4D, 4F-4G, 5A) have lightly to deeply inscribed grooves on their lateral surfaces that generally follow the curvature of the horn. Although these grooves are impressed into the surface of even the smallest horn cores, they only become pronounced on larger more mature specimens.

Numerous subadult and adult-sized nasal horn cores display a distinctive rostral overgrowth of surficial bone (Fig. 4A4C) that drapes down over the underlying bone about onethird of the way up the anterior margin of the horn and continues around onto the lateral surface to the level of the base of the horn. This overgrowth and its associated groove may be related to the attachment of the keratinous sheath that covered the horn in life. This feature is only poorly developed on adult nasals of $C$. apertus and is never seen on its subadult-sized nasals. Notably the margin of this "overgrowth" occurs in the same position and inscribes the same 
Fig. 3. Selected cranial elements of Centrosaurus brinkmani, n. sp. (A) TMP 2002.68.3, parietal, dorsal view; TMP 2002.68.1, holotype parietal: (B) dorsal view, (C) close-up of left parietal processes P1-P3 ornamentation, caudal view; TMP 2002.68.10, postorbital (D) right lateral view, (E) caudal view; (F) TMP 2002.68.5 (right) anterior view. EO, extra ossification; F, frontal; O, orbit; OHC, orbital horn core; P1-P3, parietal processes; PB, palpebral; PBS, palpebral suture; PF, prefrontal; SOH, supraorbital horn; TG, transverse groove. Scale bar $=10 \mathrm{~cm}$.

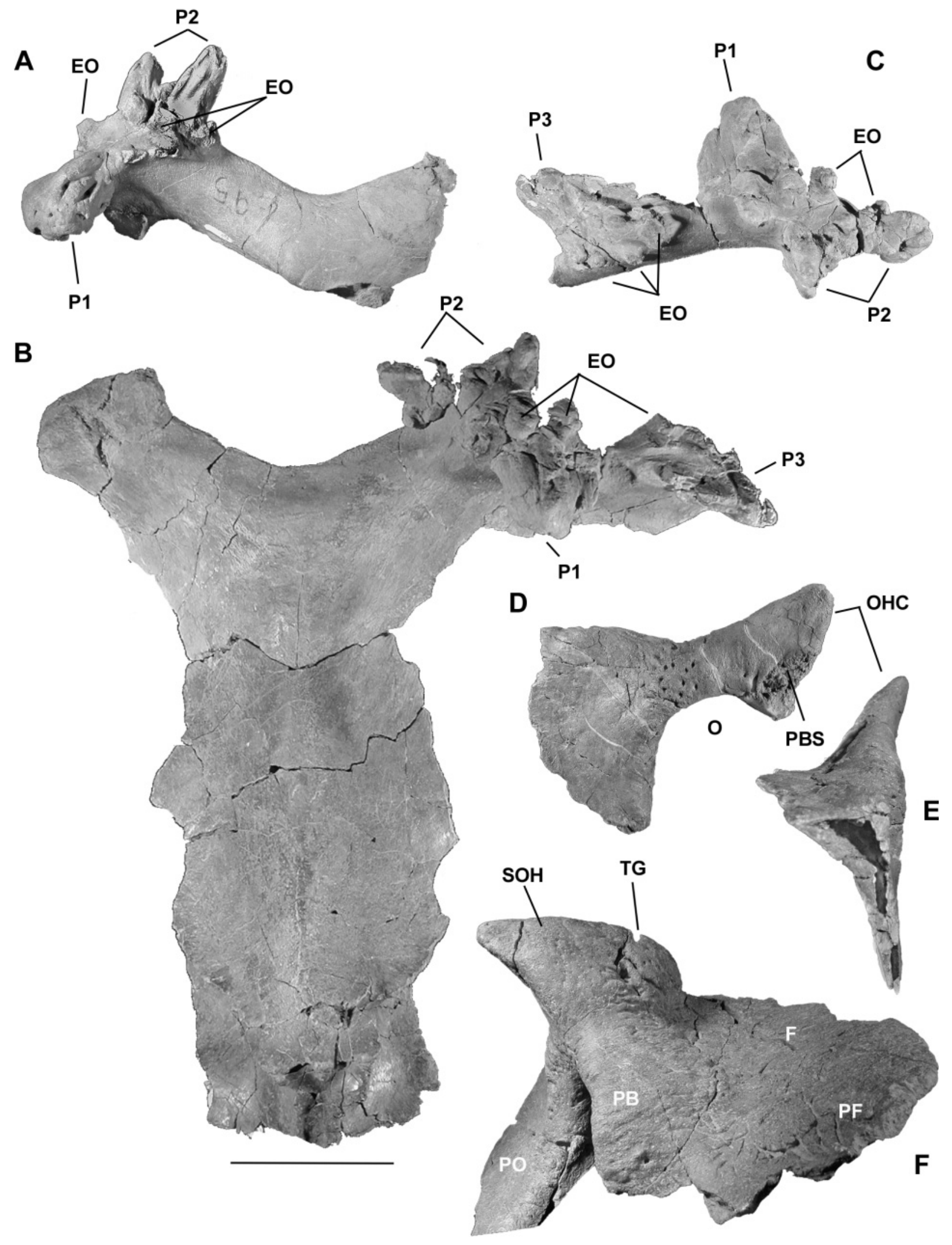


Fig. 4. Centrosaurus brinkmani, n. sp, nasals. TMP 2002.68.6: (A) right lateral view, (B) anterior view; TMP 2002.68.7: (C) left lateral view; TMP 2002.68.9: (D) left lateral view, (E) medial view; TMP 2002.68.8: (F) lateral view, (G) medial view. BV, beveling; NO, nasal overgrowth. Scale bar $=10 \mathrm{~cm}$.

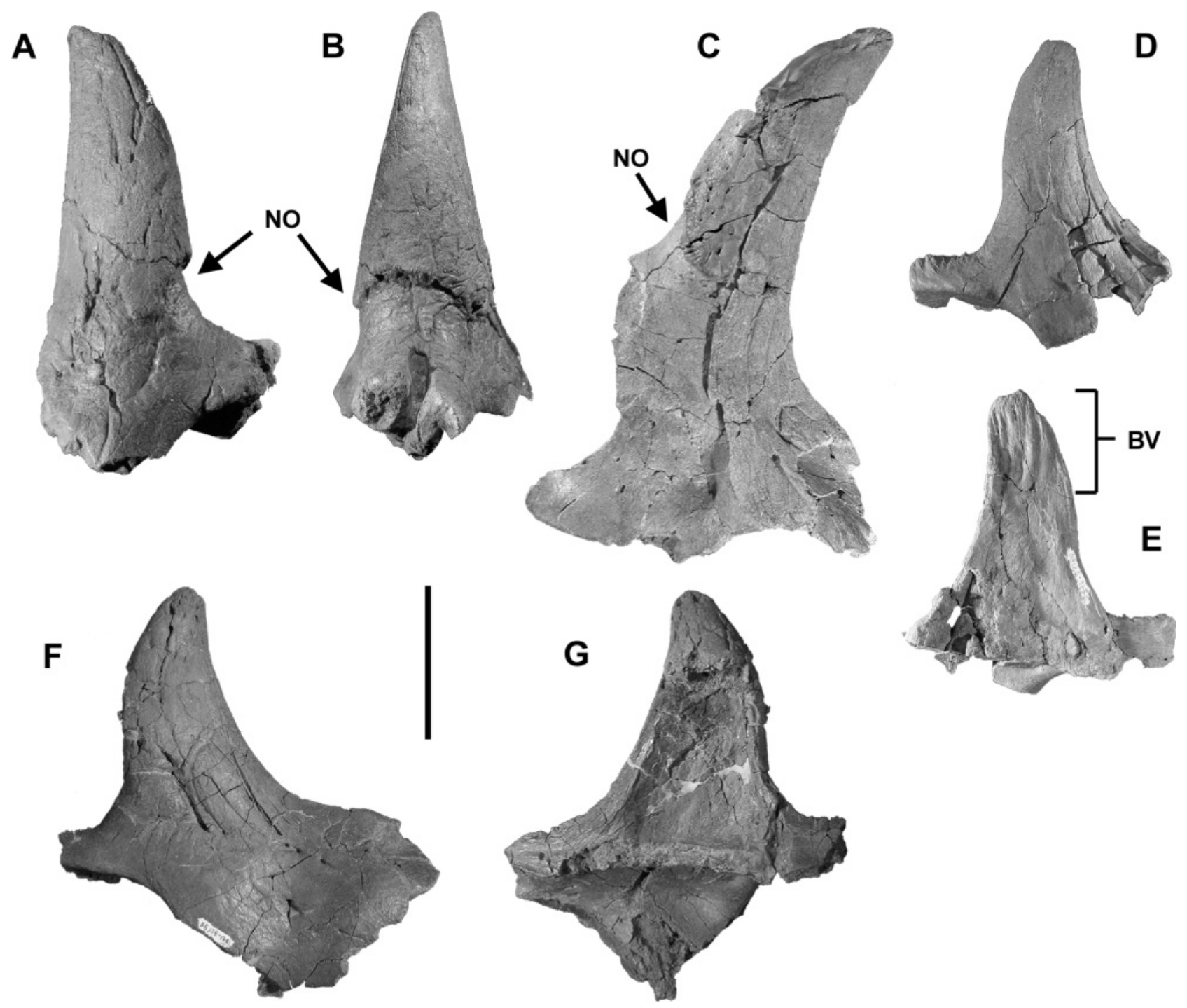

outline as does the impression of the arcuate vessel on the nasal horn of Triceratops (i.e., Forster 1996a, fig.1). No indication of this vessel has been noted previously for centrosaurines.

\section{Supraorbital region}

As in all ceratopsids, the postorbital bears the orbital horn. In large adult-sized centrosaurines, the postorbital is incorporated into the supraorbital through fusion with the frontal, lacrimal, and prefrontal, with the palpebral being variably fused into the unit. The supraorbitals contact each other along the medial surfaces of the frontals. In adults, the adjacent vaulted frontals form the medial portion of the dorsal skull roof and enclose most of the supracranial cavity with the prefrontals contributing anteriorly and the lacrimals anterolaterally. The supracranial cavity opens dorsally on the midline via the elongated frontal fontanelle that can become secondarily closed in old, mature ceratopsids.

Moderately large $C$. apertus postorbitals have an orbital horn that is roughly pyramid-shaped with a dorsally directed horn, the height of which is equal to its basal length. Postorbitals of C. brinkmani (Fig. 3D, 3E, 6A, 6B) differ from those of $C$. apertus, of similar size, in bearing horns that typically have a horn height to basal length ratio of $2: 1$ or greater, are depressed (i.e., appear "flattened" rather than pyramidal), and have a pronounced rostrolateral inclination. The base of the lateral surface of the horn above the orbit has a slight concave depression.

On large mature $C$. apertus supraorbitals, the horns have one of two morphologies. The first, which is the inflated form (e.g., TMP 80.18. 221, Ryan et al. 2001, fig. 3.12I), is followed ontogenetically by the second, which is the remodelled (= development of supraorbital pits) form. In the former, the horn exhibits a great increase in robustness, losing its pyramidal shape and sharply defined tip as the medial surface and lateral margin "swell." The medial and, to a lesser extent, the lateral surface become highly rugose, developing deep grooves running parallel to the long axis of the 
Fig. 5. Centrosaurus brinkmani, n. sp., partial skulls. (A) TMP 98.12.69, right dorsal oblique view; TMP 99.82.2: (B) dorsal view, (C) right lateral view. F, frontal; FF, frontal fontanelle; N, nasal; NHC, nasal horn core; O, orbit; P, parietal; PB, palpebral; PO, postorbital; $\mathrm{SOH}$, supraorbital horn; SOP, supraorbital pitting. Scale bar $=10 \mathrm{~cm}$.

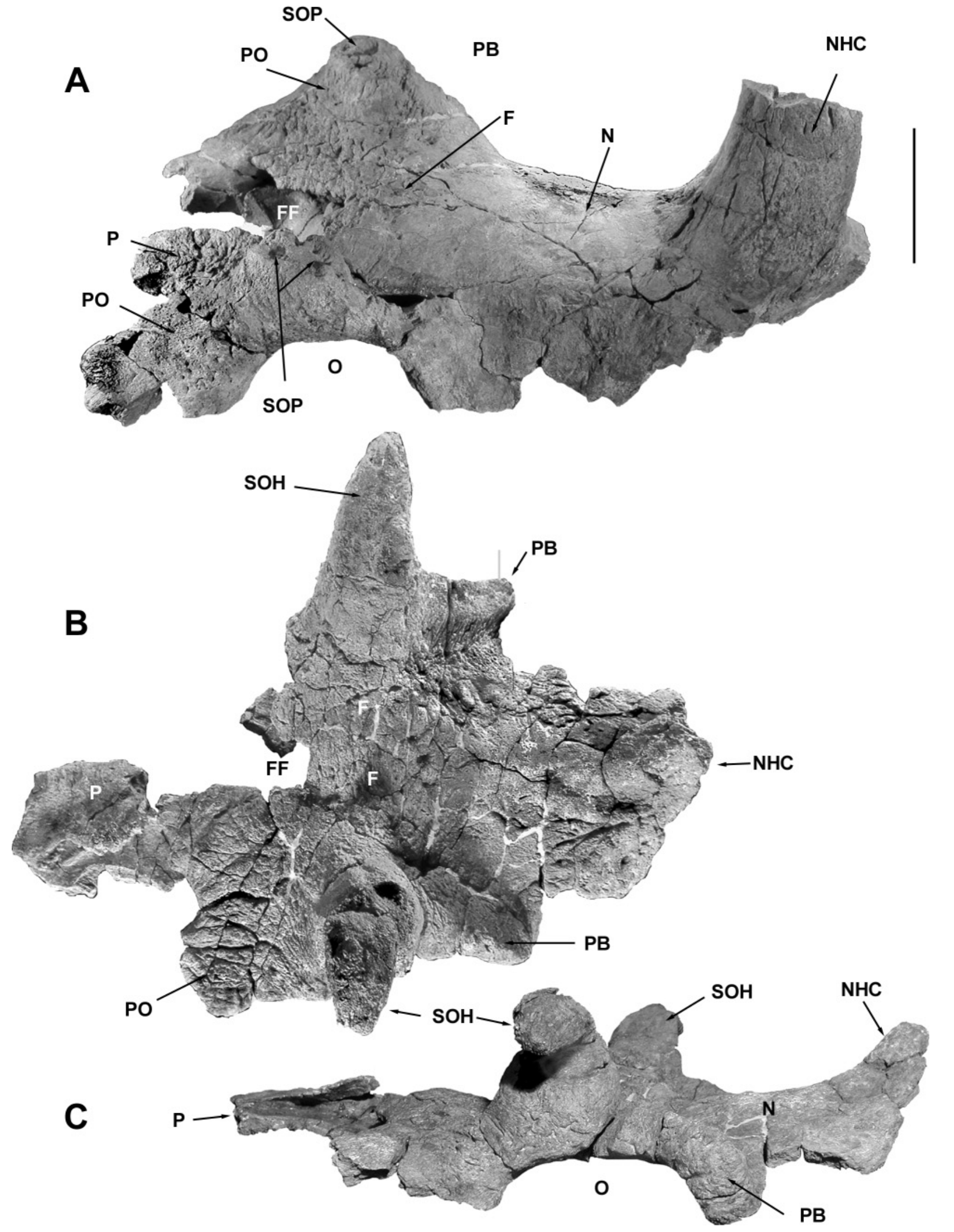

(C) 2005 NRC Canada 
Fig. 6. Centrosaurus brinkmani, n. sp. TMP 2002.68.11, right postorbital: (A) left lateral view; (B) medial view; TMP 2002.68.12, right supraorbitals: (C) dorsomedial view; (D) lateral view; TMP 2002.68.13: (E) posterior view, (F) lateral view. F, frontal; LS, contact for laterosphenoid; O, orbital; OHC, orbital horn core; PB, palpebral; PBS, palpebral suture; SCC, supracranial cavity; SOH, supraorbital horn; SQ, contact for squamosal; TG, transverse groove. Scale bar $=10 \mathrm{~cm}$.

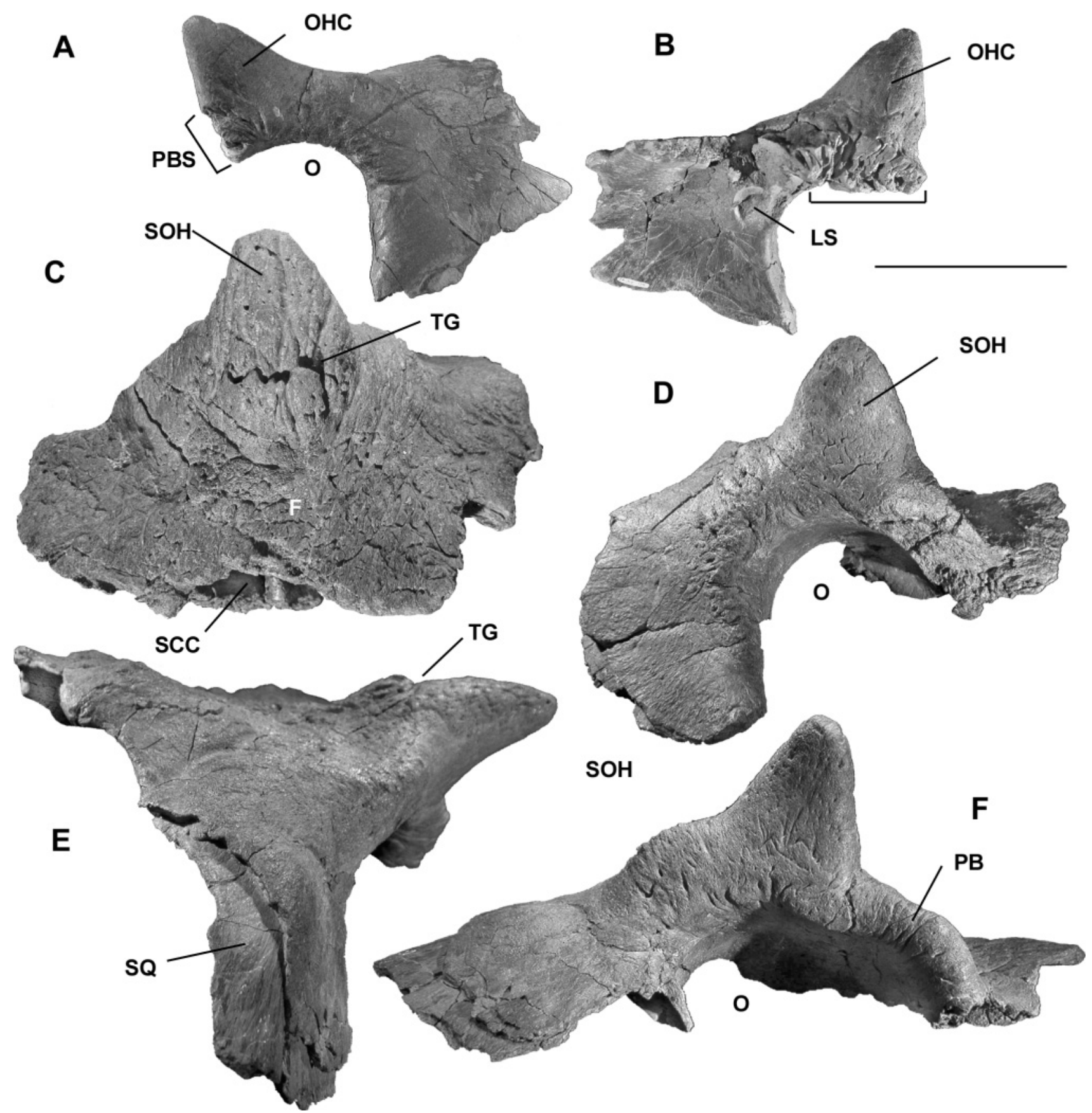

horn. This inflation of the horn appears to precede development of supraorbital pits in the second "remodelled" morphology. During this phase, the horn core can be completely eroded away (see Sampson et al. 1997 and Ryan et al. 2001 for a complete description of this process for various centrosaurines). Large mature $C$. brinkmani supraorbital horns (Fig. 3F; 6C-6F) also underwent similar "inflation," which is additionally accompanied by a marked flexion of the horn laterally or rostrolaterally, before they developed supraorbital pitting. Adult specimens of $C$. brinkmani, from which the supraorbital horn has been obliterated by supraorbital pitting (e.g., TMP 98.12.69, Fig. 5A), have ornamentation that is indistinguishable from that of $C$. apertus showing similar pitting.

On the supraorbitals of $C$. brinkmani, the longitudinal grooves on the medial surface anastomose at a point approximately one-quarter of the distance above the skull roof forming a horizontal groove here designated the transverse groove 
Fig. 7. Generalized illustrations of the parietals of (A) Centrosaurus brinkmani and (B) Centrosaurus apertus parietal processes, P1P7. Scale bar $=10 \mathrm{~cm}$.
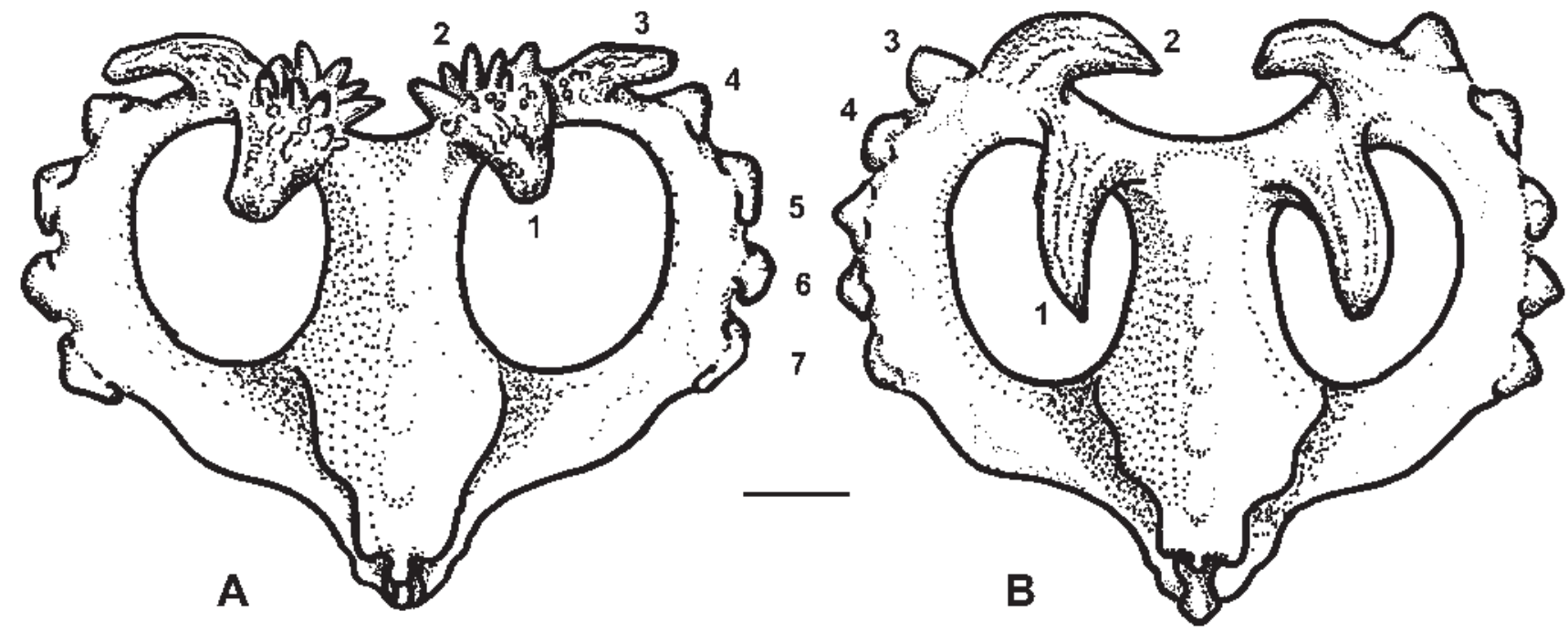

(Fig. 3F, 6C, 6E). This groove typically marks the point on the medial surface of large adult-sized specimens where the horn core angles laterally away from the skull. The groove appears to widen ontogenetically.

\section{Frill}

The ceratopsid frill is composed of the parietal and squamosals with epoccipitals variably fusing to the margins of each element. The parietals form the sagittal and, at least, the caudal rami of the frill, whereas the squamosals form the anterolateral (centrosaurines) or lateral (chasmosaurines) rami. Together with the squamosals, the parietals enclosed the paired parietal fenestrae, which are secondarily closed in the mostderived chasmosaurines.

The parietal with its ornamentation is perhaps the most important element for establishing relationships within the Centrosaurinae. The squamosal is highly conservative across all centrosaurines, other than Avaceratops, and will not be discussed further.

\section{Parietal}

Most adult-sized ceratopsids develop a number of homologous ornamental processes at specific loci (first seen ontogenetically as the scalloped emarginations of the juvenile parietal) on the posterior and lateral parietal rami, through fusion of an epoccipital to the underlying parietal, and the subsequent modification of the conjoined structure. Each process and underlying locus has been assigned a sequential number (Fig. 7) (i.e., P1-P7; Sampson et al. 1997, figs. 2, 10), beginning with the locus closest to the sagittal midline. On centrosaurines, there are typically seven loci (occasionally eight and rarely six).

The adult-sized parietal of $C$. brinkmani has the same general shape as that of $C$. apertus, including the presence of homologous parietal processes. Although no complete parietals were recovered from either bone bed, the shape of the parietal and its ornamentation can be confidently inferred from the numerous multiple overlapping sections of fragmentary parietals that were collected (Fig. 7A).

Centrosaurus brinkmani is notable for having as an autapomorphy numerous small extra (or accessory) dermal ossifications (Fig. 3A-3C, 8A, 8E, 8F, 8H) that fuse to the parietal along its dorsal and caudal margins and that are clustered around the first three parietal processes. These ossifications are randomly developed as short (10-70 mm) spines that are variably fused along portions of their adjacent margins and (or) fused to the bases and margins of P1-P3. The examination of broken extra ossifications reveals that they can be hollow and weakly attached to the parietal. Some of the extra ossifications continued to expand ontogenetically and took on ribbon-like forms that covered the surfaces of some P1 and P2 processes, fusing them together into single masses. This feature is best seen on TMP 99.82.1 (Fig. 9A, 9B), the most complete parietal collected from the MRR BB. Although the surface of the fused processes has been eroded, their overall shape and minimum size at maturity can readily be determined.

Like $C$. apertus, $C$. brinkmani has a recurved hook-like P1 process, and a $\mathrm{P} 2$ with a medially oriented component (Fig. 3A-3C, 7A, 8E, 8F, 9A, 9B). The P1 processes that were recovered are shorter and less robust than those typically seen on $C$. apertus, and their underlying shape is always at least partially obscured by the fused extra ossifications. On the holotype TMP 2002.68.1 (Fig. 3b, 3c), the LP1 process is short ( $\sim 5 \mathrm{~mm}$ in length) with an oval base and terminates in a blunt apex. On its dorsal surface, several grooves run parallel to its long axis, similar to those seen on many of the P1 hooks of $C$. apertus. Ventrally, two short and narrow channels terminate in narrow ( $2-4 \mathrm{~mm}$ wide) foramina that penetrate into the body of the process. These channels appear to have formed through the coalescence of adjacent lips of narrow grooves (fragments of the P1 processes collected from BB 138 tend to have a "spongy" texture because of the presence of the multiple irregular grooves that penetrate their interiors). The surface of the process is covered by small ossifications, and its base is surrounded by the broken bases of three extra ossifications. In life, these processes would have been directed dorsally and occupied the surface between the $\mathrm{P} 1$ and $\mathrm{P} 2$ processes. As in $C$. apertus, the supporting parietal is thickest through the base of the $\mathrm{P} 1$ process and 
Fig. 8. Centrosaurus brinkmani, n. sp. TMP 2002.68.14: (A) parietals, caudal view with P2 epoccipitals and sutures in caudoventral view, (B) close-up of modified long-grain (MLG) bone texture from the dorsal surface; TMP 2002.68.15 (juvenile): (C) ventral view, (D) close up of long-grain (LG) and mottled (MT) bone textures; TMP 2002.68.4, P1 and P2 ornamentation: (E) ventral view, (F) caudal view; (G) TMP 2002.68.16, P3 process; (H) TMP 2002.68.17 (subadult), P1 process, ventral view with small extra ossifications at base. EO, extra ossifications; P1-P3, parietal processes; P2S, suture for P2 epoccipital. Scale bars $=10 \mathrm{~cm}$.

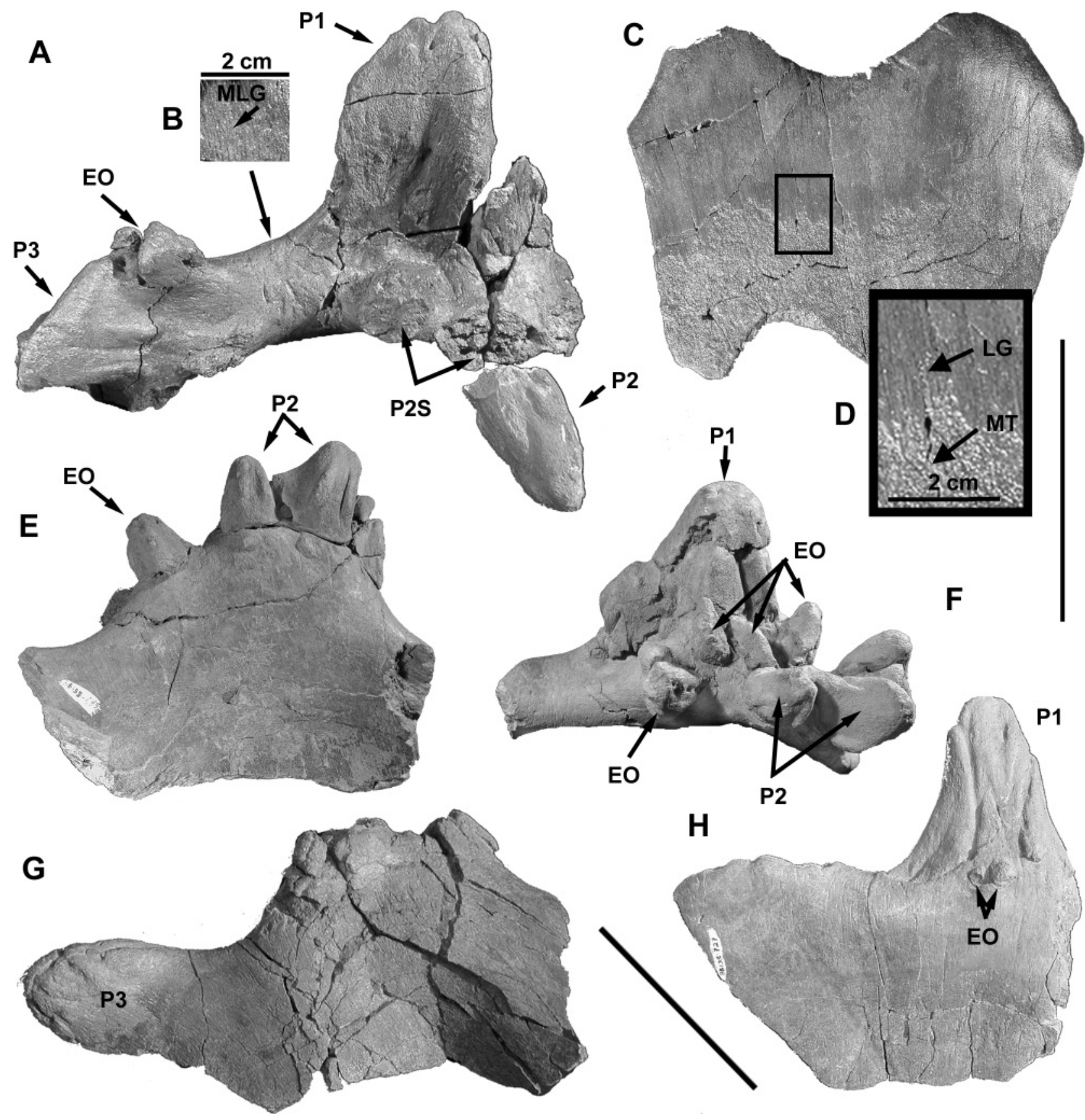

thins to a relatively constant thickness on the lateral rami that is roughly equal to the thickness of the epoccipitals lateral to the P3 process.

The P2 process of $C$. brinkmani does not form the same distinctive medially curled, tapered hook seen on $C$. apertus and many specimens of $S$. albertensis. Rather, it is formed by one or more elongated, caudally- to caudomedially-directed epoccipitals that are supplemented by extra ossifications (Fig. 3A-3C, 9A). The LP2 process of the holotype TMP 2002.68.1 (Fig. 3B, 3C) consists of several laterally spreading, short spike-like epoccipitals that are partially fused along their adjoining surfaces and are ringed by small bead-like ossifications. The main portion of LP2 is a short $(50 \mathrm{~mm})$ medially projecting epoccipital that has a roughly triangular cross-section, with two distinct grooves on each of its medial and dorsal surfaces. Lateral to the medially directed process of P2 is a second larger epoccipital that projects dorsolateral to the medial process. The compound nature of the $\mathrm{P} 2$ process is best illustrated on TMP 2002.68.3 (Fig. 3A), TMP 2002.68.1 (Fig. 3B, 3C), TMP 2002.68.14 (Fig. 8A), and TMP 2002.68.4 
Fig. 9. Centrosaurus brinkmani, n. sp. TMP 99.82.1, parietals: (A) close-up of parietal ornamentation, caudal view, (B) dorsal view; (C) TMP 92.30.41, ventral view. P1-P3, parietal processes; VO, ventral overgrowth of parietal processes; P3B, base of P3. Scale bar = $10 \mathrm{~cm}$.

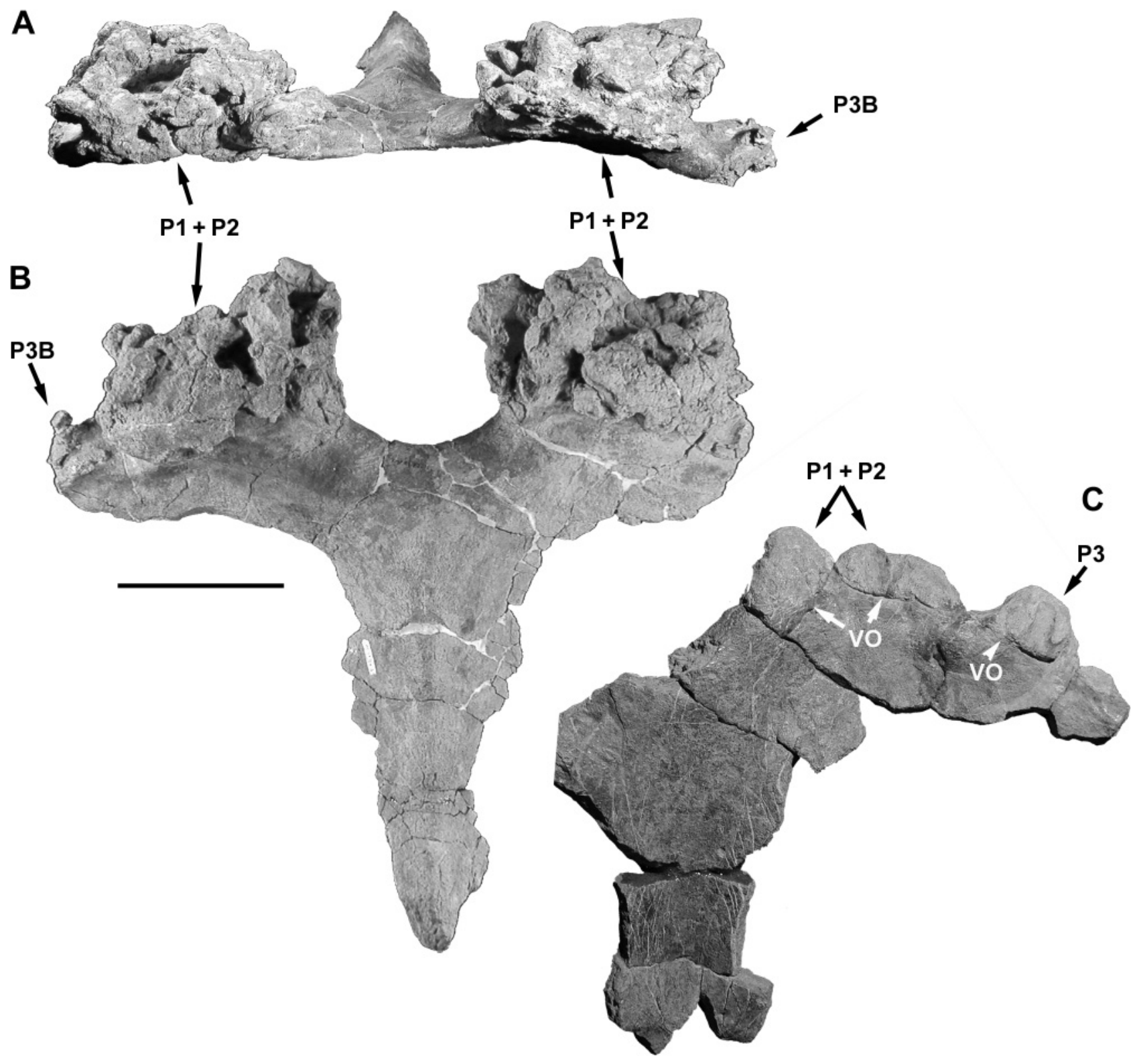

(Fig. 8E, 8F). The former preserves the one of the two main epoccipitals of the $\mathrm{P} 2$ process (unfused) and the open suture for the second.

As seen on the parietal from the MRR quarry (TMP 99.82.1, Fig. 9A, 9B), these processes continued their development until P1and P2 formed a single coossified structure that includes rostrally procurved and caudomedially projecting processes homologous to the $\mathrm{P} 1$ and $\mathrm{P} 2$ processes, respectively. As in $C$. apertus, the $\mathrm{P} 1$ process is a robust procurving hook, but all specimens available for study suggest that it is relatively shorter and more irregularly shaped than that of $C$. apertus.

Unlike the unmodified P3 epoccipitals seen on all specimens of $C$. apertus, this process in C. brinkmani takes the shape of either a dorsoventrally oriented blunt hook (e.g., TMP 2002.68.16, Fig. 8G) or a tapered spike (Fig. 3B, 3C) (character 13). It is intermediate in size between that of $C$. apertus and all other centrosaurines that possess robust spikes at this parietal locus. The P3 process is separated from the processes adjacent to it by a short (typically 10 $30 \mathrm{~mm}$ ) saddle-shaped notch on the caudal margin of the parietal. The notch is more pronounced on the medial side of the P3 process because the parietal is thicker on this side. As in $C$. apertus, the $\mathrm{P} 3$ process marks the point of transition from the posterior parietal ramus to the lateral parietal ramus, essentially marking the "corner" of the frill.

As is the case for all $\mathrm{P} 2$ and $\mathrm{P} 3$ processes of $C$. brinkmani, their ventral bases are inflated and distinctly offset from the 
smooth texture of the underlying ventral parietal surface. This feature is best seen on the parietals from the MRR quarry (e.g., TMP 92.30.41, Fig. 9C) and is not present on $C$. apertus or any other centrosaurine.

The remaining $\mathrm{P} 4-\mathrm{P} 7$ processes of $C$. brinkmani closely resemble the unmodified, depressed, and crescentic epoccipitals of centrosaurines other than Styracosaurus. On larger specimens, these processes have the distinctive imbrication (sensu Sampson et al. 1997) previously noted as characteristic of centrosaurines.

As is typical of the paucispecific bone beds from the Campanian of Alberta, numerous and mostly fragmentary parietals were recovered from BB 138, including nine juvenile, 27 subadult, and 73 adult-sized specimens. In addition to the almost complete parietal from the MRR BB, 27 fragments were recovered from the quarry or the immediate area during the 1998 excavation.

\section{Phylogenetic analysis}

In recent phylogenetic analyses of the Ceratopsidae, only Sereno (1986), Sampson (1995), Penkowski and Dodson (1999), and Dodson et al. (2004) have included the individual taxa comprising the Centrosaurinae. Only Sampson (1995) and Penkowski and Dodson (1999) specifically examined the Centrosaurinae. All of these agree on the monophyly of the clade and the arrangement of undisputed taxa within it, but disagree about the inclusion of taxa such as Avaceratops and Monoclonius crassus (the latter designated nomen nudum by Sampson et al. 1997) that display juvenile characteristics. Following Dodson et al. (2004), Monoclonius had been set aside from this analysis.

Avaceratops, described by Dodson in 1986, is based on the associated skeleton ANSP 15800 collected from the Careless Creek Quarry of the late Campanian Judith River Group of south-central Montana. Although the associated skeleton is relatively complete, it is missing several key diagnostic features, including the nasal, dorsal skull roof, both postorbitals, and the rostral. Sampson et al. (1997) considered the material to be from a subadult based, in part, on the thin posterior margin of its parietal, a frill (parietal + squamosal) lacking epoccipitals, and its subadult size.

In 1999, Penkowski and Dodson described a partial, large adult-sized ceratopsid skull (MOR 692) from the Judith River Formation of Montana and referred it to Avaceratops. Although this skull is referable to the Centrosaurinae, based on a single premaxillary character, its referral to Avaceratops is based on the comparison of its adult features with the juvenile features of the holotype - features that can be significantly modified through ontogeny. MOR 692 was collected $125 \mathrm{~km}$ north-northeast of the type locality of Avaceratops and is not associated with juvenile or subadult-sized material that would strengthen their argument. Whereas MOR 692 may eventually turn out to be the adult form of Avaceratops, such an association at this time is unwarranted. Following Dodson et al. (2004), we have set Avaceratops aside from this analysis.

Styracosaurus ovatus is based on a single incomplete parietal from the Two Medicine Formation of Montana. It has been excluded from this analysis because the large amount of uncertainty that would be introduced owing to missing data.
Pachyrhinosaurus n. sp. is based on new undescribed material collected from bone beds near Grande Prairie, Alberta. Material from this taxon has long been available for study, and the taxon was previously included in the analysis of Sampson (1995). It is also included here.

\section{Materials and methods}

To construct a hypothesis of the phylogenetic relationships within the Ceratopsidae, a cladistic analysis was conducted using 17 cranial characters for seven ingroup taxa (Achelosaurus horneri, C. apertus, Einiosaurus procurvicornis, Pachyrhinosaurus canadensis, Pachyrhinosaurus n. sp., S. albertensis, and $C$. brinkmani) and two outgroups: (1) the combined character set for Protoceratops and Zuniceratops, and (2) the Chasmosaurinae. Postcranial characters were excluded because, firstly, the two ceratopsid subfamilies are diagnosed almost exclusively on cranial characters; secondly, complete postcranial material is even less well known for some taxa than is the cranial material; and thirdly, postcranial characters have proven to be of limited utility in higher level ceratopsid diagnoses (Chinnery 2004). Characters used in this study include those taken or adapted from previously published works (i.e., Sereno 1986; Forster et al. 1993; Sampson 1995; Forster 1996b; and Holmes et al. 2001), as well as newly defined characters. Modifications or redescriptions of previously published characters are noted where appropriate (Appendix A).

Several characters $(1,2,5,6,7,11,12,13,14$, and 16) are polymorphic (Table A1). Traditionally polymorphic characters are avoided because they are often difficult to polarize and order. However, because variation among the ceratopsids is principally contained within the cranial ornamentation, these apomorphies are usually difficult to subdivide into valid separate characters in such a way that they are either completely independent of each other or so that they do not result in the addition of a large amount of missing data to the data set if they are excluded. The analysis was run with the data coded as unordered.

All characters were optimized using the delayed transformation option (DELTRAN). The data matrix was analyzed using the Exhaustive Search option of the Branch-and-Bound option in Phylogenetic Analysis Using Parsimony (PAUP, version $4.0 \mathrm{~b} 10$ for Windows).

Finally, the data set was subjected to a bootstrap analysis using all characters to assess the support for the generated clades. The bootstrap analysis does this by determining the number of times each clade appears in searches for shortest trees using resampled matrices, thus giving an indication of the relative support for each clade in a given tree (Hillis and Bull 1993).

\section{Results}

One most-parsimonious tree (Fig. 10) of 34 steps was obtained from the analysis (consistency index $(\mathrm{CI})=0.941$; retention index $(\mathrm{RI})=0.913)$, supporting the hypothesis of C. brinkmani as the sister taxon to C. apertus. Centrosaurus is supported by two unambiguous characters (11 and 14) and one ambiguous character (12); the latter is the multi-state morphology of the P2 process. Centrosaurus brinkmani is supported by four characters $(5,12,13$, and 16), of which 5 and 13 are unambiguous. Bootstrap support for the basal 
clades (Ceratopsidae and Centrosaurinae) was 100\% with other clades ranging from $60 \%$ (Styracosaurus + (Einiosaurus + (Achelosaurus + Pachyrhinosaurus))) to $84 \%$ (Pachyrhinosaurus canadensis and $P$. n. sp.)

\section{Discussion}

Centrosaurus brinkmani (Fig. 11) is the sister taxon of $C$. apertus, differing only in attributes of its cranial ornamentation. The juvenile-sized postorbital horn core of C. brinkmani most closely resembles that of $C$. apertus, but it can be easily distinguished by the relatively longer horn length and the depressed rather than pyramidal shape (character 5). It is always oriented rostrolaterally, suggestive of the more pronounced lateral inflection seen later in ontogeny on the adult-sized supraorbitals. It also tends to have a slight concavity on its lateral surface, just above its base, whereas that same region in $C$. apertus is flat (this feature is not consistently present and has not been included as a character in the phylogenetic analysis). The elongated shape of these postorbital horns is suggestive of the horns seen on many chasmosaurines. Although poorly known, small juvenile chasmosaurine horn cores (e.g., the small juvenile Triceratops (UCMP 154452) from the Hell Creek Formation of Montana (Goodwin et al. 1997)), are almost indistinguishable from centrosaurine material of the same size. Larger Triceratops postorbitals (e.g., SMNH P2299.1, SMNH P2623.1) from the Frenchman Formation of Saskatchewan (Tokaryk 1997) are similar in size to those of the typical C. brinkmani subadult postorbital horn cores (horn height $\sim 150 \mathrm{~mm}$ ), but the Triceratops horn cores can be distinguished by their oval bases and distinctly conical shape, which distinguishes them from those of any centrosaur. The two ceratopsid subfamilies appear to resemble each other in postorbital horn core morphology early in ontogeny, but they quickly develop their distinctive characteristics as they grow.

As for adult supraorbitals of $C$. apertus, the palpebral forms the anterior portion of the orbit and contributes to only the anteriormost base of the horn core. The ovoid palpebral suture on juvenile- and adult-sized $C$. brinkmani postorbitals is large and covers the lower one-half of the horn cores' rostral and rostrolateral surface, which indicates that the palpebral was progressively excluded from the horn core as the animal grew.

Although the majority of unmodified $C$. apertus supraorbital horn cores are dorsally oriented, two examples of from this taxon (NMC 343 and UALVP 11345) have horn cores that are rostrolaterally oriented (although neither is as pronounced as that exhibited by $C$. brinkmani), and at least one can be attributed to postmortem distortion. While we recognize that the two Centrosaurus species do rarely exhibit similar adult-sized supraorbital horn morphology, we emphasize that the dorsal orientation of the supraorbital horn core is unknown for $C$. brinkmani, and a lateral orientation of the horn core has only rarely been recognized in the hundreds of $C$. apertus specimens collected. Additonally, the juvenile- and subadult-sized postorbitals of the two taxa are not known to overlap in morphology and can easily be distinguished from each other.

The development of the medially placed transverse groove on the supraorbital horn core of C. brinkmani deserves further comment because it appears to be related to the development of the supraorbital bosses on the geologically younger Pachyrhinosaurus from Late Cretaceous of Alberta. The supraorbital boss (more typically a shallow, transversely grooved, cup-shaped depression) of Pachyrhinosaurus (e.g., TMP 89.55.139) is formed by extensive remodelling of the dorsal surface of the postorbital as part of its ontogenetic development. The dorsal surface of the fully developed supraorbital boss is traversed internally by a series of rugose ridges (e.g., TMP 89.55.427) that run roughly perpendicular to the long axis of the postorbital. Similar ridges also develop within the transverse grooves of both $C$. apertus (e.g., TMP 80.18.221) and C. brinkmani (e.g., TMP 2002.68.5) as continuations of the longitudinal grooves on the medial surface of the horn core across the transverse groove as it widens during ontogeny. This is particularly noticeable on larger, putatively older $C$. brinkmani supraorbital horn cores (e.g., TMP 2002.68.5), whose extreme lateral flexion is enhanced by the widening of the transverse groove. Such specimens give the impression that the distal portion of the horn is splitting away from its proximal portion as the transverse groove widens, although this is unlikely to be the actual case. Careful examination of the surface of the splayed transverse groove on these specimens shows that the longitudinal grooves on the lower portion of the transverse groove closely resemble the ridges that cross the supraorbital horns of Pachyrhinosaurus. On Centrosaurus specimens that have lost the proximal portion of the horn through the development of resorption pits, the remaining portion of the ornamentation can, in some cases, form structures that are similar in morphology to that seen on Pachyrhinosaurus. It is possible that the process of supraorbital maturation exhibited by C. brinkmani represents a foreshadowing of a stage in the development of supraorbital ornamentation in Pachyrhinosaurus n. sp.

Numerous juvenile- and subadult-sized parietal fragments from both bone beds document the pattern of development of the parietal processes and the extra ossifications. The extra dermal ossifications (character 16) first appear on the caudoventral margins of subadult parietals as small beads of bone (e.g., TMP 2002.68.17, Fig. 8h) before becoming further elaborated with maturity. Presumably these dermal ossifications are of the same origin as the epoccipitals, and their development as short spines is similar to the development of the midline parietal spikes seen on the new pachyrhinosaur from Grand Prairie, Alberta.

The parietal processes, including P2, appear to begin development and proceed as previously outlined for $C$. apertus (see Sampson et al. 1997; Ryan et al. 2001). Unlike any other centrosaurine, the $\mathrm{P} 2$ process of $C$. brinkmani is ultimately composed of at least one traditional epoccipital (character 12) that is augmented by several extra ossifications of similar size and shape, such that the original P2 epoccipital may not be easily discerned.

On all parietals recovered from BB 138, the P1 and P2 processes appear to remain distinct from each other, although the dorsal parietal surface lying between them may have one or more extra ossifications growing from the surface. The partially eroded parietals recovered from the MRR BB indi- 
Fig. 10. Cladistic relationships of the Centrosaurinae. Characters (1-17) and states (superscripts 0-4) as outlined in Appendix A. Percent support for clades from bootstrap analysis (5000 replicates) are listed in italics above each of the branches.

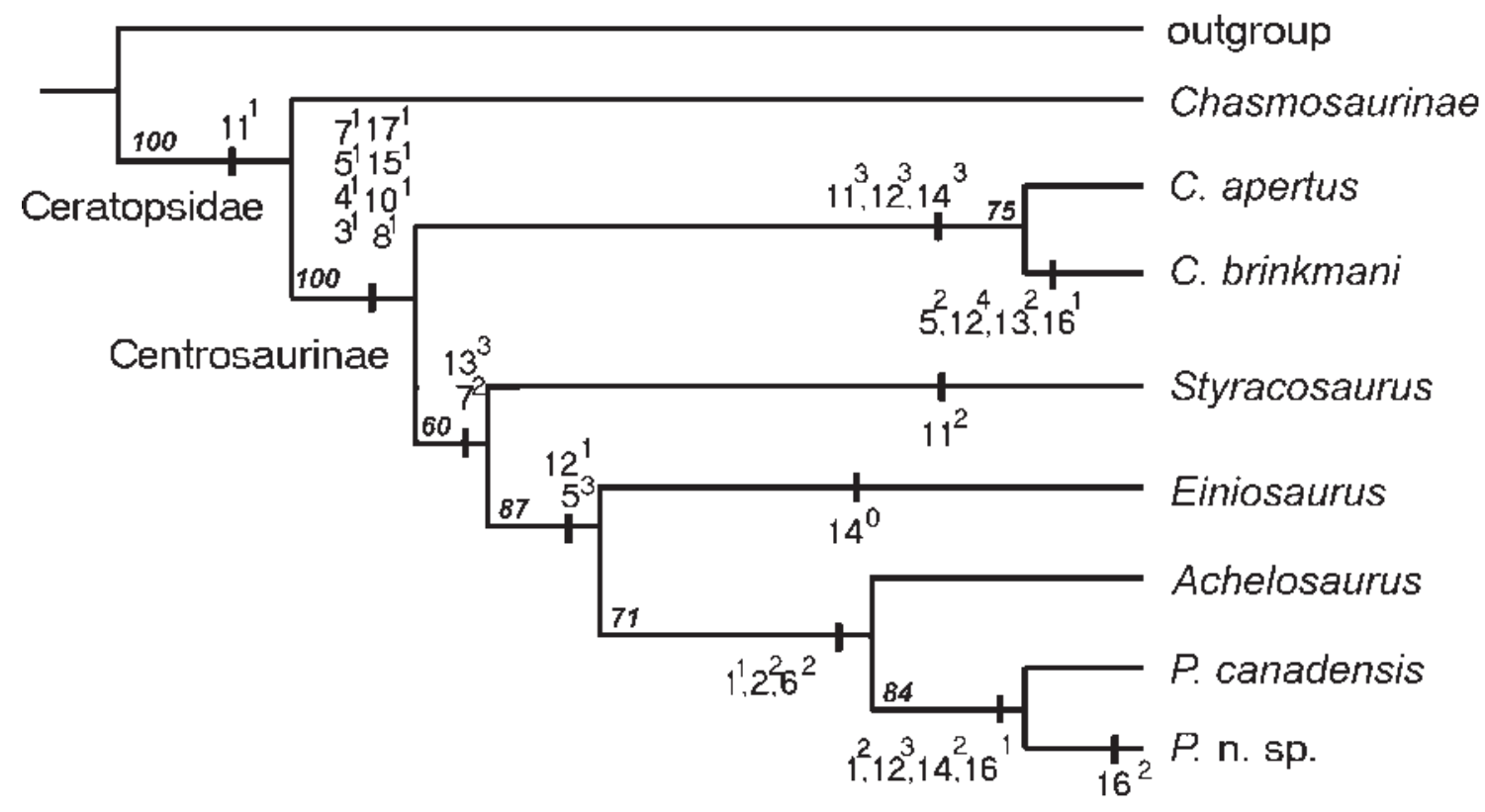

Fig. 11. Life reconstruction of the head of an adult-sized Centrosaurus brinkmani, n. sp., based on holotype parietal TMP 2002.68.1, parietal TMP 2002.68.3, partial skulls TMP 98.12.69 and TMP 99.82.2, and nasal TMP 2002.68.6.

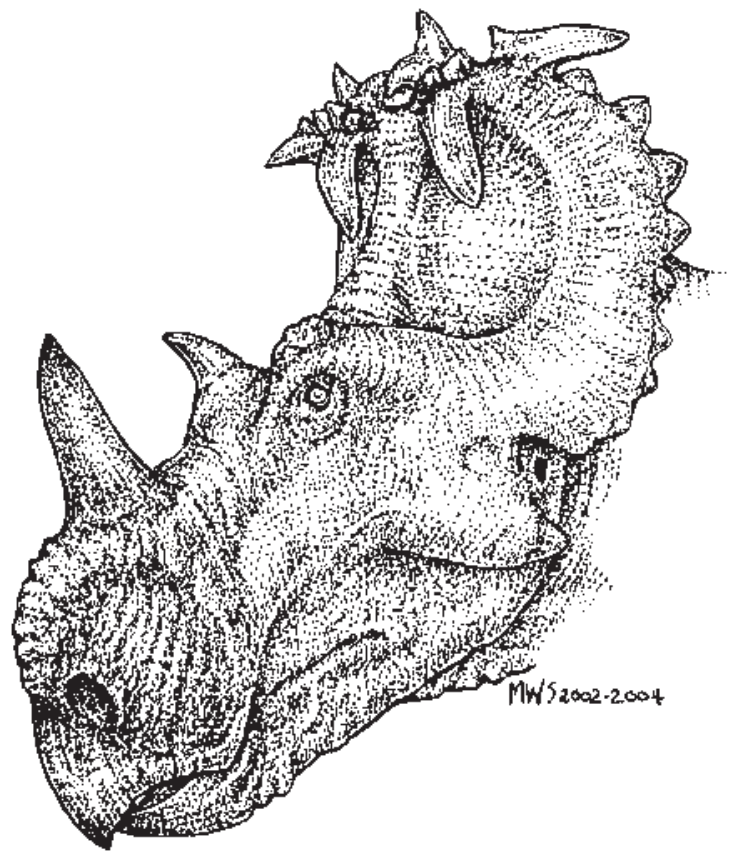

cate that, as the P1 and P2 ornamentation developed, their bases, if not the entire structure, fused to become one larger unit.

One difference between the parietals obtained from the two quarries is in the shape of their posterior parietal margins. Parietals from the MRR BB have a narrow $U$ shape, which is also shared with Achelosaurus, Einiosaurus, Pachyrhinosaurus, and Styracosaurus (all of which possess spike-like processes at parietal locus 3). Parietals collected from BB 138 have a much broader margin separating the $\mathrm{P} 2$ processes and more closely resemble the posterior parietal margin of C. apertus. It is possible that the difference in shape is owing to the degree of development and fusion of the P1 and P2 processes, as seen in the parietals from the two localities, or that it is the result of individual or geographical variation. It is entirely possible that, with the collection of additional specimens, the parietal material from the MRR BB may be recognized as being specifically distinct from the material from BB 138.

The shape of the fused nasal horn core of the new taxon closely resembles that of $C$. apertus, except for the presence on most specimens of a crescent-shaped overgrowth of bone on its anterior surface, which may be related to the attachment of the keratinous sheath that would have been present in life. This feature may be an autapomorphy for the taxon but, until a larger sample is obtained for study, it is not designated as such here.

\section{Taphonomy}

Based on the taphonomic data collected from the two bone beds (Ryan 2003), both BB 138 and the MRR BB represent paucispecific, channel lag-like deposits (sensu Rogers 1993 ) that probably accumulated over long (>10 and probably $>10^{2}$ ) years after having been abraided for periods of time (probably $>10$ years) while in a channel. The actual origin of the material within the bone beds cannot be determined, but Ryan et al. 2001 suggested that death of large aggregations of ceratopsids in the late Campanian of Alberta could be because of drowning, possibly as the result of the flooding of the low-lying regions adjacent to the Western Interior Seaway caused by periodic large storms.

Previously, Sampson et al. (1997) formalized the use of bone texture in determining the relative age of ceratopsid (typically skull) elements. Small- to medium-sized elements 
that lacked or showed only the early stages of development of cranial ornamentation were recognized as having "longgrained" and "mottled" bone texture, respectively, (Fig. 8B, 8D). Large adult-sized elements exhibiting well-developed ornamentation were recognized as having "adult" bone texture typical for the element in question. C. brinkmani elements recovered from the two bone beds differ from the centrosaurine material examined in those original papers (Achelosaurus, C. apertus, Pachyrhinosaurus, and Styracosaurus) in having many examples of bone texture on parietals adjacent to the ornamentation exhibiting what is here designated as "modified long-grain bone texture" (MLG). This texture resembles the long-grain texture seen on juvenile- and subadultsized specimens of other centrosaurines and C. brinkmani, but its elongated grains are wider and deeper on C. brinkmani. The MLG appears to persist onto the largest cranial elements recovered from $\mathrm{BB} 138$ and takes the place of the traditional "adult" bone texture. Most cranial elements collected from the MRR BB have at least the superficial bone texture eroded enough to make the determination of the presence of MLG texture difficult.

It is possible that long-grained texture on C. brinkmani persists for a longer period of time on adult-sized elements than is evident for other centrosaurines, and that the elongated grains of MLG might simply be the expression of long-grain texture on larger elements. It is also possible that the adult-sized elements collected from the bone beds may not be the actual adult size for the ceratopsid, and that a more "typical" adult bone texture would appear once the centrosaur reached mature size and full expression of its ornamentation.

\section{Stratigraphy}

In Dinosaur Provincial Park, the $C$. brinkmani bone bed lies $14.8 \mathrm{~m}$ below the regional disconformity that separates the Oldman and the Dinosaur Park formations. The first occurrence of $C$. apertus (BB 168) occurs $<1 \mathrm{~m}$ above the disconformity and the taxon is the only centrosaurine in the lower $30 \mathrm{~m}$ of the Dinosaur Park Formation. It is replaced in the upper portion of the formation by S. albertensis (Fig. 1). In Dinosaur Provincial Park, bentonites $4 \mathrm{~m}$ below the disconformity have been dated at $76.5 \pm 0.5 \mathrm{Ma}$ (Eberth and Braman 1993). Based on a sediment accumulation rate for the Oldman Formation of $5.0-6.0 \mathrm{~cm} / 1000$ years (Eberth and Braman 1993) and the location of the C. brinkmani bone bed below the disconformity, the two Centrosaurus species were separated by between 250000 to 300000 years in the Dinosaur Provincial Park region.

The $C$. brinkmani material from the MRR BB in southern Alberta cannot be accurately placed in section because of the limited outcrop in the area, but it does occur $\sim 70 \mathrm{~m}$ below the dated bentonite (76 Ma; Eberth and Brinkman 1994) at the Devil's Coulee nesting site, which lies $\sim 4 \mathrm{~km}$ to the northwest. Based on a sedimentation rate for the Oldman Formation of 5.0-6.0 cm/year (Eberth and Braman 1993), the age of the MRR locality is between 77.2 and 77.6 Ma. This slightly older age may account for differences apparent between the materials recovered from the two localities. These two occurrences of $C$. brinkmani give it a known geographic span of $\sim 170 \mathrm{~km}$.

Although $C$. brinkmani and a single specimen of $C$. apertus both occur within the Oldman Formation, they appear to not have overlapped temporally. The Oldman and Dinosaur Park formations of Alberta were derived from one of two Campanian-aged clastic wedges that accumulated separately from the northwest and the southwest (Eberth and Hamblin 1993). The Oldman Formation represents a portion of the southern wedge and consists of deposits of a low-sinuosity ephemeral fluvial system that originated in the southern Cordillera of Canada and Montana and flowed northeastward (Braman et al. 1995). The Dinosaur Park Formation represents the southern portion of the northern wedge and comprises deposits of a high-sinuosity fluvial to estuarine system that originated in the north and central Cordillera (Eberth and Hamblin 1993). During the Bearpaw transgression of the late Campanian, as the shoreline shifted westward, the clastic wedge from which the Dinosaur Park Formation was derived migrated southward, overstepping the wedge from which the Oldman Formation was derived (Eberth and Hamblin 1993). The contact between the Oldman and Dinosaur Park formations represents a northeast-to-southeast shift in sediment deposition in the Alberta basin. Based on the age of the disconformity, the Dinosaur Park Formation sediments arrived in the Dinosaur Provincial Park region at $76.5 \mathrm{Ma}$ (Eberth and Deino 1992) and in the Onefour region of southern Alberta at $~ 75$.Ma (Eberth et al. 1990). The rate of sedimentation in the Dinosaur Park Formation of $\sim 4 \mathrm{~cm} / 1000$ years suggests that the rate of southerly migration of the Dinosaur Park Formation was 130-140 km/Ma (Eberth and Hamblin 1993). Thus the Dinosaur Park sediments in the Onefour area of southern Alberta are equivalent to the uppermost portion of the formation in Dinosaur Provincial Park. Based on sedimentation rates for the region where the $C$. apertus specimen was recovered from the Oldman Formation of southern Alberta, it is stratigraphically equivalent to the lower Centrosaurus-Corythosaurus faunal zone (Ryan and Evans 2005) of the Dinosaur Park Formation in Dinosaur Provincial Park. Thus the $C$. apertus from southern Alberta is the southernmost occurrence of this taxon, which suggests that it was living in a different environment than its more northern members in the Dinosaur Provincial Park Region.

\section{Discussion of centrosaurine systematics}

The phylogenetic analysis of the Centrosaurinae confirms the monophyly of the group and establishes the sister taxa relationship of $C$. apertus and $C$. brinkmani. Centrosaurus brinkmani is supported by four autapomorphies: the shape and inflection of the subadult-sized postorbital horn cores (character 5), the multi-part nature of the P2 process (character 12), the shape of the P3 process (character 13), and the presence of small additional dermal ossifications on the caudal parietal rami (character 16).

Here, the extra ossifications are considered to be homologous with the midline parietal spikes of Pachyrhinosaurus n. sp., but each occurs on different circumscribed regions of the parietal and takes a different terminal morphology. Centrosaurus brinkmani also appears to be unique among ceratopsids in having distinctly raised ventral margins of the most medially placed parietal processes and a rostral overgrowth of bone on the nasal horn core. However, owing to the small sample size, we have not included these as characters of $C$. brinkmani in this analysis. These characters may 
be regarded as autapomorphies of $C$. brinkmani if and when more material is collected and their potential variation is better understood.

The clade of (Styracosaurus + (Einiosaurus + (Achelosaurus + Pachyrhinosaurus))) is supported by two unambiguous characters (7 and 13). Each of the taxa in this clade lacks a pronounced supraorbital horn in adults (Achelosaurus and Pachyrhinosaurus have supraorbital bosses), and each taxon has long narrow spikes at parietal locus P3. Styracosaurus albertensis is supported by one unambiguous character (11), which it shares with the type and only specimen of $S$. ovatus (USNM 11869). The latter specimen consists of only a partial parietal and will be evaluated in a separate paper. Styracosaurus albertensis is also the only centrosaurine to have the parietal processes $\mathrm{P} 4-\mathrm{P} 7$ variably developed as short spikes (USNM 11869 also has its only P4 locus developed as a short spike).

The (Einiosaurus + (Achelosaurus + Pachyrhinosaurus $)$ ) clade is supported by one unambiguous (5) and one ambiguous character (12). This latter character (form of the P2 process) undergoes a reversal in Pachyrhinosaurus. Retrieval of this clade corroborates the findings of Sampson (1995) and Penkowski and Dodson (1999).

Einiosaurus also has one autapomorphy — a strongly procurved nasal horn core. In the original description of Einiosaurus, Sampson (1995) noted the shape of its nasal horn core as being dimorphic, based on the referral to Einiosaurus of MOR 492, with a straight elongate nasal horn core. However, this specimen does not come from the same bone bed as the original Einiosaurus material and cannot be directly associated with it. Additionally, other Einiosaurus specimens from the Two Medicine Formation of Montana all possess the procurved nasal, which suggests that this is its natural and only state. It is possible that MOR 492 is referable to the poorly known $S$. ovatus, which is found in the same region.

The (Achelosaurus + Pachyrhinosaurus) clade is supported by three unambiguous characters (1, 2, and 6). Despite its superficial similarity to Pachyrhinosaurus, Achelosaurus can be defined by the length of its nasal boss, which, unlike that of Pachyrhinosaurus, is restricted to the nasals and does not extend up onto the frontals.

The (Pachyrhinosaurus canadensis and $P$. "n. sp") clade is supported by two unambiguous characters (1 and 14) and two ambiguous characters (12 and 16). Pachyrhinosaurus canadensis was named and described by Sternberg (1950), who advocated placing it in a separate family (Pachyrhinosauridae) based on its then unique nasal shape and supraorbital ornamentation. The original type and referred material incorporates several partial skulls, including nasal and supraorbital bosses, but the parietal is only poorly understood from isolated elements. Pachyrhinosaurus canadensis possesses the P3 parietal spike of $P$. " $n$. sp." but it lacks the midline parietal spike-like process.

The latter taxon is from late Campanian bone beds near Grande Prairie, Alberta. The material is in the process of being formally described. Currie (personal communication, 2004) indicates that it has more autapomorphies than have been reported here (i.e., the prominent midline parietal spike). The (Pachyrhinosaurus + Achelosaurus) clade can be infor- mally referred to as the "pachyrhinosaurs" based on their synapomorphies of nasal and supraorbital bosses.

Based on the analysis presented here, several trends are apparent within the Centrosaurinae. In general, supraorbital horn cores decrease in size - passing from the largest horns seen on the centrosaurs $C$. brinkmani and $C$. apertus to the reduced horns of Styracosaurus to the transformation into bosses in Achelosaurus and Pachyrhinosaurus. This putative transformation series may be related in some way to the development of supraorbital resorption pitting, which may play a role in the development of bosses in the derived Achelosaurus and Pachyrhinosaurus.

The development of the P1 and P3 parietal processes also seems to be inversely related. Centrosaurus brinkmani has moderately well-developed P1 processes and short but elaborated P3 processes. Centrosaurus apertus has the most extensively developed P1 processes but lacks any elaboration of the P3 process. All more-derived centrosaurines have welldeveloped P3 spikes but completely lack (Achelosaurus, Einiosaurus, and Pachyrhinosaurus) or only have poorly developed (Styracosaurus) P1 processes.

The key adult cranial ornamentations important for the phylogenetic analysis of the centrosaurines have phases of development that overlap. Adult examples of the supraorbital ornamentations of $C$. apertus and $C$. brinkmani have overlapping morphologies, even though the unmodified horn cores of the latter are typically longer with a different orientation than those of most specimens of $C$. apertus. Both species of Centrosaurus have modified supraorbital horn cores that can resemble those of Styracosaurus and some specimens of Pachyrhinosaurus. The nasal and parietal ornamentations are more useful in distinguishing taxa but only for adult specimens, because juvenile- and subadult-sized specimens can show a confusing overlap of forms, especially on fragmentary material.

These results support the observation that the ceratopsids are a tight-knit group in which the pattern of relationships between the members can only be teased apart using a relatively small number of polymorphic cranial characters, primarily those relating to ornamentation of the nasal, parietal, and supraorbital regions. In previous phylogenetic analyses (Sampson 1995; Penkowski and Dodson 1999), the coding of cranial characters was relatively straightforward, with little overlap between character states. The addition of $C$. brinkmani to the Centrosaurinae clade has brought new character states to the analyses that make it more difficult to describe these in discreet units. As new ceratopsids continue to be discovered, we predict that resolution of cladistic patterns will become poorer, not better, because new forms will fill in the morphological gaps between previously known taxa.

\section{Acknowledgments}

We would like to thank the TMP and its Field Experience and affiliated Volunteer Preparation Program for supporting this project, especially Drs. Don Brinkman, Philip Currie, David Eberth, Jim Gardner, Bruce Naylor, and Mr. Mike Getty. Staff of Dinosaur Provincial Park graciously facilitated work in BB 138. Thanks to Drs. Peter Dodson, Robert Holmes, and Hans-Dieter Sues for reviewing this paper and providing insightful comments. Many thanks to Mike Getty, Wendy 
Sloboda, and the numerous volunteers, especially Bill McPheeters and Karl Schiemann, who expertly prepared the fossils material used in this project. Wendy and Ed Sloboda and the Devil's Coulee Cooperating Society, Warner, Alberta assisted with work at the MRR BB. Thanks to Mike Skrepnick for drawing Fig. 11 and to Chad Kerychuk of Digital Dream Machine, Edmonton, Alberta, who assisted with photography. Thanks to the Phaeton Group, San Francisco, California for its shared expertise. Finally, special thanks to the late Lawrence Halmrast, and his estate, for donating to the TMP portions of the historical fossil collection that he made at the MRR. This donation included material that alerted MJR to the presence of a new ceratopsid in southern Alberta. This project was supported, in part, by a Natural Science and Engineering Research Council of Canada Discovery Grant RGPIN 9745 to A.P. Russell and travel funds provided to M.J. Ryan by the Dinosaur Natural History Society, Brooks, Alberta.

\section{References}

Braman, D.R., Johnston, P.A., and Haglund, W.M. 1995. Canadian paleontology conference field trip guidebook no. 4: Upper Cretaceous paleontology, stratigraphy and depositional environments at Dinosaur Park and Drumheller, Alberta. Canadian Palaeontology Conference V, Drumheller '95, Royal Tyrell Museum of Palaeontology, 29 September - 2 October 1995.

Brown, B. 1914. A complete skull of the horned dinosaur Monoclonius, from the Belly River of Alberta. Bulletin of the American Museum of Natural History, 33: 549-558.

Brown, B. 1917. A complete skeleton of the horned dinosaur Monoclonius, and description of a second skeleton showing skin impressions. Bulletin of the American Museum of Natural History, 35: 709-716.

Chinnery, B.J. 2004. Morphometric analysis of evolutionary trends in the ceratopsian postcranial skeleton. Journal of Vertebrate Paleontology, 24: 591-609.

Dodson, P. 1986. Avaceratops lammersi: a new ceratopsid from the Judith River Formation of Montana. Proceedings of the Academy of Natural Sciences of Philadelphia, 138: 305-317.

Dodson, P. 1990. On the status of the ceratopsids Monoclonius and Centrosaurus. In Dinosaur systematics: approaches and perspectives. Edited by P.J. Currie and K. Carpenter. Cambridge University Press, Cambridge, UK., pp. 231-243.

Dodson, P., Forster, C.A., and Sampson, S. D. 2004. Ceratopsia. In The Dinosauria. Edited by D.B. Weishampel, P. Dodson, and H. A. Osmólska. The University of California, Berkeley, Calif., pp. 494-513.

Eberth, D.A., and Braman, D.R. 1993. Selected Upper Cretaceous section of the southern Alberta Plains: the Judith River Group, Horseshoe Canyon Formation, Whitemud, Battle, and the Scollard formations, and the Cretaceous-Tertiary boundary. In Geological Association of Canada - Mineralogical Association of Canada, Field Trip Guidebook, Joint Annual Meeting, Edmonton, Alta., 1993, 84 p.

Eberth, D.A., and Brinkman, D.B. 1994. Sequence stratigraphy, depositional environments and paleoecology of the Judith River Group (Upper Cretaceous), southern Alberta. In Exploration update '94. Canadian Society of Petroleum Geologists, fieldguide PR-3, Calgary, Alta., 69 p.

Eberth, D.A., and Deino, A.A. 1992. Geochronology of the nonmarine Judith River Formation of southern Alberta. In Mesozoic of the western interior. Society of Economic Paleontologists and Mineralogists, 1992 theme meeting, Ft. Collins, Colo., 24 p.

Eberth, D.A., and Hamblin, A.P. 1993. Tectonic, stratigraphic, and sedimentological significance of a regional disconformity in the upper Judith River Formation (Belly River Wedge) of southern Alberta, Saskatchewan and northern Montana. Canadian Journal of Earth Sciences, 30: 174-200.

Eberth, D.A., Braman, D.R., and Tokaryk, T.T. 1990. Stratigraphy, sedimentology, and vertebrate paleontology of the Judith River Formation (Campanian) near Muddy lake, west-central Saskatchewan. Bulletin of Canadian Petroleum Geology, 38: 387-406.

Forster, C.A. 1996a. New information on the skull of Triceratops. Journal of Vertebrate Palaeontology, 16: 246-258.

Forster, C.A. 1996b. Species resolution in Triceratops: cladistic and morphometric approaches. Journal of Vertebrate Palaeontology, 16: 259-270.

Forster, C.A., Sereno, P.C., Evans, T.W., and Rowe, T. 1993. A complete skull of Chasmosaurus mariscalensis (Dinosauria: Ceratopsidae) from the Aguja Formation (late Campanian) of west Texas. Journal of Vertebrate Paleontology, 13: 161-170.

Godfrey, S.J., and Holmes, R. 1995. Cranial morphology and systematics of Chasmosaurus (Dinosauria: Ceratopsidae) from the Upper Cretaceous of western Canada. Journal of Vertebrate Paleontology, 15: 726-742.

Goodwin, M.B., and Deino, A.L. 1989. The first radiometric ages from the Judith River Formation (Upper Cretaceous), Hill County, Montana. Canadian Journal of Earth Sciences, 26: 1384-1391.

Goodwin, M.B., Clemens, W.A., and Horner, J.R. 1997. Morphological variation and ontogeny in the skull of Triceratops. Journal of Vertebrate Paleontology, 17A: 49A.

Hillis, D.M., and Bull, J.J. 1993. An empirical test of bootstrapping as a method for assessing confidence in phylogenetic analysis. Proceedings of the National Academy of Sciences, 90: 8939-8941.

Holmes, R.B., Forster, C.A., Ryan, M., and Sheperd, K.M. 2001. A new species of Chasmosaurus from the Dinosaur Park Formation of Southern Alberta. Canadian Journal of Earth Sciences, 38: 1423-1438.

Lambe, L.M., 1902. On vertebrata of the Mid-Cretaceous of the Northwest Territory, part 2. New genera and species from the Belly River Series (Mid-Cretaceous). Canadian Geological Survey, Contributions to Canadian Paleontology, 3: 25-81.

Lambe, L.M. 1904. On the squamoso-parietal crest of two species of horned dinosaurs from the Cretaceous of Alberta. Ottawa Naturalist, 8: 81-84.

Langston, W., Jr. 1959. Anchiceratops from the Oldman Formation of Alberta. National Museum of Canada Historical Papers, 3, 11 p.

Lehman, T.M. 1990. The ceratopsian subfamily Chasmosaurinae: sexual dimorphism and systematics. In Dinosaur systematics: approaches and perspectives. Edited by P.J. Currie and K. Carpenter. Cambridge University Press, Cambridge, UK., pp.211-299.

Lerbekmo, J.F, and Braman, D.R. 2002. Magnetostratigraphic and biostratigraphic correlation of late Campanian and Maastrichtian marine and continental strata from the Red Deer Valley to the Cypress Hills, Alberta, Canada. Canadian Journal of Earth Sciences, 39: 539-557.

Penkowski, P., and Dodson, P. 1999. The morphology and systematics of Avaceratops, a primitive horned dinosaur from the Judith River Formation (late Campanian) of Montana, with the description of a second skull. Journal of Vertebrate Paleontology, 19: 692-711.

Rogers, R.R. 1993. Systematic patterns of time-averaging in the terrestrial vertebrate record; Two Medicine - Judith River interval, Montana. Journal of Vertebrate Palaeontology, 13A: 55-56. 
Ryan, M.J. 2003. Taxonomy, systematics and evolution of Centrosaurine Ceratopsids of the Campanian western interior basin of North America. Unpublished thesis, University of Calgary, Calgary, Alta.

Ryan, M.J., and Evans, D. 2005. A review of the Ornithischia of Dinosaur Provincial Park. In Dinosaur Provincial Park. Edited by P.J. Currie and E. Koppelhus. Indiana University Press, Bloomington, Ind., pp. 312-348.

Ryan, M.J., and Russell, A.P. 2001. The dinosaurs of Alberta (exclusive of Aves). In Mesozoic vertebrate life: new research inspired by the paleontology of Philip J. Currie. Edited by D. Tanke and K. Carpenter. Indiana University Press, Bloomington, Ind., pp. 279-297.

Ryan, M.J., Russell, A.P., Currie, P.J., and Eberth, D.A. 2001. Taphonomy of a Centrosaurus (Dinosauria: Ornithischia) bone bed from the Dinosaur Park Formation (Campanian) of Alberta, Canada with comments on cranial ontogeny. Palaios, 16: 482-506.

Sampson, S.D.1995. Two new horned dinosaurs from the upper Cretaceous Two Medicine Formation of Montana, with a phylogenetic analysis of the Centrosaurinae (Ornithischia: Ceratopsidae). Journal of Vertebrate Paleontology, 15: 743-760.

Sampson, S.D., Ryan, M.J., and Tanke, D.H. 1997, Craniofacial ontogeny in centrosaurine dinosaurs (Ornithischia: Ceratopsidae): taphonomic, behavioral and phylogenetic implications. Zoological Journal of the Linnean Society, 121: 293-337.

Sereno, P.C. 1986. Phylogeny of the bird-hipped dinosaurs (Order Ornithischia). National Geographic Research, 2: 234-256.

Sternberg, C.M. 1940. Ceratopsidae from Alberta. Journal of Paleontology, 14: 468-480.

Sternberg, C.M. 1950. Pachyrhinosaurus canadensis, representing a new family of Ceratopsia. Bulletin of the National Museum of Canada, 118: 109-120.

Tokaryk, T.T. 1997. First evidence of juvenile ceratopsians (Reptilia: Ornithischia) from the Frenchman Formation (late Maastrichtian) of Saskatchewan. Canadian Journal of Earth Sciences, 34: 1401-1404.

\section{Appendix A. Characters used in phylogenetic analysis}

1. Nasal ornamentation, basal length (adult) (this study)

(0) short-based, $<5 \%$ basal skull length

(1) long-based, between $10 \%$ and $20 \%$ basal skull length

(2) long-based, $>25 \%$ basal skull length

All ceratopsids with nasal horns have short basal lengths relative to those of the bosses seen on Achelosaurus and Pachyrhinosaurus. The nasal boss of Pachyrhinosaurus is relatively longer than that of Achelosaurus because it extends onto the frontals in this taxon. (Sampson 1995).

2. Nasal ornamentation type (adult) (Sampson 1995; Holmes et al. 2001)

(0) absent or poorly developed

(1) elongated horn

(2) boss

As noted by Holmes et al. 2001, all basal ceratopsians previously classified as protoceratopsids lack nasal ornamentation, except for some specimens of Protoceratops that show a bilateral dorsal swelling on the dorsal surface of the nasals and Bagaceratops that can have a small condensed horn. All centrosaurines have juvenile- and subadult-sized nasals that bear a thin triangular or blade-like structure that develops into a horn or boss after the paired elements fuse during ontogeny. All adult chasmosaurines carry a short nasal horn that is formed by a separate element (epinasal) in at least some taxa.

3. Nasal horn height (adult) (after Sampson 1995; after Holmes et al. 2001)

(0) short, height of horn $\leq 20 \%$ basal skull length

(1) long, height of horn $>20 \%$ of basal skull length

The horn cores of mature Centrosaurus and Styracosaurus nasals are always longer than those of mature chasmosaurines.

4. Narial spine of nasal, a pronounced process projecting rostrally into the nasal vestibule from the caudal narial margin

(0) absent

(1) present

This process is formed primarily from the nasal, but its ventral surface can include a contribution ventrally from the dorsocaudal portion of the premaxilla (Sereno 1986).

5. Form of postorbital ornamentation (subadult) (after Sampson 1995; Foster et al. 1993; Holmes et al. 2001)

(0) height at least three times as long as rostrocaudal basal length; apex dorsally or anterodorsally oriented

(1) pyramidal horn core with $\sim 1: 1$ ratio of height to rostrocaudal basal length; apex dorsally oriented

(2) elongate pyramidal horn core (attenuated) with $>1.5: 1$ ratio of height to rostrocaudal length; apex anterolaterally oriented

(3) horn core longer rostrocaudally than high, with rounded apex; apex dorsally oriented

The height of the postorbital horn is measured from a point above the orbit that is equal to the minimum thickness through the orbit immediately caudal to the horn. On a small postorbital its height is effectively equal to its height above the top of the frontal suture. The shape and height of the Styracosaurus postorbital has recently been determined by the preparation of new material (e.g., Ryan 2003). Juvenileand subadult-sized chasmosaurine postorbital horns are poorly known outside of Triceratops.

6. Supraorbital ornamentation type (unmodified adult) (Sampson 1995)

(0) absent

(1) present, horn

(2) present, boss

All unmodified adult ceratopsids develop either horns or bosses. Reduced and shortened supraorbital horns of adults are seen in both subfamilies. The low rounded horns seen on a few adult-sized supraorbitals of Styracosaurus appear to represent a reduction of a Centrosaurus-like pyramidal subadult postorbital horn without the intermediary development of a larger horn. As on some putatively old, mature $C$. apertus and $C$. brinkmani supraorbitals, the supraorbital ornamentation characteristic of Styracosaurus can be further modified and lost by the development of supraorbital pits (e.g., the holotype skull of $S$. albertensis, NMC 344). The development of these pits is a synapomorphy of the Ceratopsidae, as it is known for specimens of Chasmosaurus and possibly Triceratops (e.g., NAMAL 110), and can result in extreme changes to the supraorbital ornamentation of these taxa throughout the latter part of their ontogeny. Similarly, the bosses of Achelosaurus and Pachyrhinosaurus appear to have developed directly from the small rounded horns seen on the juvenile and subadult postorbitals of these animals. 
Fig. A1. Character Matrix

\begin{tabular}{|c|c|c|c|c|c|c|c|c|c|c|c|c|c|c|c|c|c|}
\hline Chara & & & & & & & & & & & & & & & & & \\
\hline Taxon & 1 & 2 & 3 & 4 & 5 & 6 & 7 & 8 & 9 & 10 & 11 & 12 & 13 & 14 & 15 & 16 & 17 \\
\hline Outgroup & 0 & 1 & 0 & 0 & 0 & 0 & 0 & 0 & 0 & 0 & 0 & 0 & 0 & $\mathrm{~N}$ & 0 & 0 & 0 \\
\hline C. brinkmani & 0 & 1 & 1 & 1 & 2 & 1 & 1 & 1 & 1 & 1 & 3 & 4 & 2 & 3 & 1 & 1 & 1 \\
\hline Styracosaurus & 0 & 1 & 1 & 1 & 1 & 1 & 2 & 1 & 1 & 1 & 2 & 2 & 3 & 1 & 1 & 0 & 1 \\
\hline Achelosaurus & 1 & 2 & 1 & 1 & 3 & 2 & $\mathrm{~N}$ & 1 & 1 & 1 & 0 & 1 & 3 & 1 & 1 & 0 & 1 \\
\hline Pachyrhinosaurus n. sp. & 2 & 2 & $\mathrm{~N}$ & 1 & 3 & 2 & $\mathrm{~N}$ & 1 & 1 & 1 & 0 & 3 & 3 & 2 & 1 & 2 & 1 \\
\hline P. canadensis & 2 & 2 & $\mathrm{~N}$ & 1 & $\mathrm{~N}$ & 2 & $\mathrm{~N}$ & 1 & 1 & 1 & 0 & 3 & 3 & 2 & 1 & 1 & 1 \\
\hline Chasmosaurine & 0 & 1 & 0 & 0 & 0 & 1 & 0 & 0 & 0 & 0 & 1 & 2 & 1 & $\mathrm{~N}$ & 0 & 0 & 0 \\
\hline \multicolumn{18}{|l|}{ Raw outgroup codingss } \\
\hline Protoceratops & 0 & 1 & 0 & 0 & $\mathrm{~N}$ & 0 & $\mathrm{~N}$ & 0 & 0 & 0 & 0 & 0 & 0 & $\mathrm{~N}$ & 0 & 0 & 0 \\
\hline
\end{tabular}

All chasmosaurines, except $C$. belli, C. russelli, and C. irvinensis, have long supraorbital horns. The former two taxa have previously been described as dimorphic (Godfrey and Holmes 1995) for supraorbital horn length, having "short" (= Centrosaurine-like) and "long" (i.e., longer than Centrosaurus but shorter than half the basal skull length) morphs, but the variation in length is most likely because of the variable development of supraorbital pitting. $C$. irvinensis lacks supraorbital horns, but this is also probably owing to modification and loss of the horns by supraorbital pitting (sensu Sampson et al. 1997) and is not an autapomorphy of this species (contra Holmes et al. 2001). C. mariscalensis differs from the other three congeners in having large robust horns.

7. Supraorbital horn core shape (unmodified adult) (after Sampson 1995)

(0) elongate with pointed apex and round to oval base

(1) pyramidal with rounded apex, at least as tall as base is long

(2) rounded apex, base longer than horn is tall

In centrosaurines Centrosaurus and Styracosaurus and at least some taxa of chasmosaurines (e.g., Chasmosaurus), these horns can undergo extensive remodeling via the development of supraorbital pitting. The pitting can result in the significant reduction or complete loss of the horns on many large adultsized specimens.

8. Length of squamosal relative to parietal (Sereno 1986)

(0) equal or subequal in length

(1) squamosal $<60 \%$ total parietal length

9. Shape of medial margin of squamosal (after Dodson 1986; Penkowski and Dodson 1999)

(0) bowed (not "stepped-up")

(1) caudal portion "stepped-up" relative to rostral portion (sensu Dodson 1986)

Ceratopsids with relatively short squamosals have the caudal portion of these elements (caudal to the ventral paraoccipital groove) "stepped-up" relative to the rostral margin. Chasmosaurines have relatively long squamosals with bowed medial margins.

10. Parietal contact on caudal edge of squamosal (this study)

(0) ventrodorsally overlapping suture
(1) wide medial concave surface

Although previously described in many published descriptions of the squamosal, this element can be distinguished to the level of subfamily based on even small caudomedial fragments. On centrosaurines, this portion of the squamosal forms a wide buttress-like parietal suture with the anterolateral face of the lateral parietal rami. On some specimens the parietal suture may form an elongate concave depression, with a variably beveled surface, to meet the parietal. The development of the beveling tends to increase with the size of the element, but it appears to be highly variable. On chasmosaurines the caudomedial surface of the squamosal always tapers to a thin margin that variably overlaps the lateral parietal rami, depending on the species.

11. Process at locus 1 (after Sampson 1995)

(0) absent

(1) unelaborated epoccipital on caudal margin

(2) short procurving hook on dorsal margin, length of hook $\leq$ diameter of base

(3) long procurving hook on dorsal margin, length of hook $\geq$ twice the diameter of base

When present on centrosaurines, the $\mathrm{P} 1$ process always forms a procurving hook of variable length. Among the chasmosaurines, only $C$. irvinensis forms a similar process, but on this taxon the process is partially fused to its adjacent modified epoccipitals.

In centrosaurines, parietal locus 1 is located medial and rostral to the posterior parietal margin. The P1 process is not expressed in Achelosaurus, Einiosaurus or Pachyrhinosaurus. In $S$. albertensis, it may be expressed as a short blunt hook that is abbreviated when compared with that of Centrosaurus. Styracosaurus ovatus appears to have one small P1 process preserved on the left side. The P1 process reaches its extreme development in Centrosaurus, where it is typically expressed as a large procurving hook. However, indicative of the variation apparently inherent in the expression of the parietal processes, one of these hooks may, in rare instances, be completely absent on one side of the frill in mature specimens, while the other is well developed. Such is the case in the holotype skull, NMC 971, where there is no indication of the left process, whereas the right one is so large it spans the parietal fenestra. In C. brinkmani, the $\mathrm{P} 1$ process is less 
well defined than it is in $C$. apertus, typically being shorter and fused to accessory ossifications that link it to the P2 process.

12. Process at locus 2 (after Sampson 1995)

(0) absent

(1) unelaborated epoccipital on caudal margin base

(2) small medially curled hook, length of hook $\leq$ length of

(3) large medially curled hook, length of hook $\geq$ twice the length of base

(4) multipronged caudally directed process

In Achelosaurus and Einiosaurus, the P2 process is expressed as a short laterally compressed, tab-shaped epoccipital. One specimen of Styracosaurus (the type skull NMC 344) also expresses this morphology, but all other specimens have the larger more robust medially curled hooks that are also seen in Centrosaurus and Pachyrhinosaurus. Styracosaurus has been coded for the latter shape. The P2 processes reach their most extreme development on some specimens of $C$. brinkmani, where the processes are formed by the fusion of two or more epoccipitals and take the shape of a caudally and caudomedially projecting, multipronged process.

In chasmosaurines, the $\mathrm{P} 2$ process is present as an unelaborated epoccipital, except in C. irvinensis, where P1-4 form short thick procurving hooks that are fused along most of their adjacent surfaces.

13. Process at locus 3 (after Sampson 1995)

(0) absent

(1) small, unelaborated epoccipital on caudal margin

(2) narrow-based hook or spike, length between one and three times basal diameter

(3) narrow-based long spike, spike length $>$ four times basal diameter

The epoccipital at locus 3 is unelaborated in all chasmosaurines (except $C$. irvinensis). The P3 of $C$. irvinensis is identical in form to its $\mathrm{P} 2$. In all centrosaurines, other than C. apertus, the $\mathrm{P} 3$ process is developed as a spike or hook-like structure that varies in orientation. In each of Achelosaurus, Einiosaurus, Pachyrhinosaurus, and Styracosaurus, P3 is a long robust spike with a basal length to spike length ratio of $\geq 1: 4$.

14. Orientation of spike-like epoccipital at locus 3 (after Sampson 1995)

(0) caudally directed

(1) caudolaterally directed

(2) laterally or rostrolaterally directed

(3) dorsolaterally directed

15. Profile of midline parietal ramus (after Sampson 1995)

(0) straight

(1) series of low rounded bumps

The midline parietal rami of all centrosaurines have typically four to seven raised "bumps" running the length of the element. The processes are best seen in profile and have an ovoid shape when viewed from above. These processes may be homologous to the rounded margins of juvenile parietals that act as loci for the fused epoccipitals. However, a point of fusion for such an element is rarely seen on any midline parietal ramus, including the new species of Pachyrhinosaurus, despite the fact that it develops a midline spike from the fusion of a separate epoccipital. This character is a modification of Sampson's (1995) character 13, which assumed that the spike was a direct outgrowth of the parietal.

16. Extra ossifications on parietal (this study)

(0) absent

(1) multiple short spikes on caudal rami

(2) one on more spikes on midline ramus

17. Orientation of the triturating surface of predentary relative to the horizontal plane of the element (sensu Lehman 1990; Forster 1996b)

(0) nearly horizontal

(1) steeply inclined laterally 